NBER WORKING PAPER SERIES

\title{
PUTTING INTEGRITY INTO FINANCE: A PURELY POSITIVE APPROACH
}

\author{
Werner Erhard \\ Michael C. Jensen \\ Working Paper 19986 \\ http://www.nber.org/papers/w19986
NATIONAL BUREAU OF ECONOMIC RESEARCH
1050 Massachusetts Avenue
Cambridge, MA 02138
March 2014

\begin{abstract}
We are indebted to Sandra Carr, Miriam Diesendruck, Anders Dillan, James Poterba, Allan Scherr, Gonneke Spits, Sue Strober, and Steve Zaffron for their willingness to share their efforts, knowledge and insights into matters relevant to this paper, and especially Kevin Murphy for his insightful challenges, questions, and comments on this paper, and his willingness to share with us his knowledge, data and exhibits relevant to executive compensation. We acknowledge our students and seminar participants for their contribution to us, in particular the critical lessons about the viability of the material and the[methodology for mastering it. We are also indebted to two anonymous referees for their valuable comments, Icriticisms, and suggestions. All errors are our responsibility. Jensen has received financial supportffrom the Harvard Business School Division of Research. Both authors are associated with the non-profittErhard-Jensen Ontological / Phenomenological Initiative (from which the authors receive no financial[benefit other than a reimbursement of travel expenses when dealing with the Initiative's activities).The purpose of the Initiative is to stimulate and support research into and the application of the ontological $/$ phenomenological perspective on human nature and behavior, and the impact of such a perspective on life, living, and self. Various management consulting and public program delivery firms (some from which the authors derive a financial benefit) utilize some of the ideas presented in this paper in their consulting activities or programs. The views expressed herein are those of the authors and do not necessarily reflect the views of the National Bureau of Economic Research.
\end{abstract}

NBER working papers are circulated for discussion and comment purposes. They have not been peerreviewed or been subject to the review by the NBER Board of Directors that accompanies official NBER publications.

(C) 2014 by Werner Erhard and Michael C. Jensen. All rights reserved. Short sections of text, not to exceed two paragraphs, may be quoted without explicit permission provided that full credit, including (C) notice, is given to the source. 
Putting integrity Into Finance: A Purely Positive Approach

Werner Erhard and Michael C. Jensen

NBER Working Paper No. 19986

March 2014

JEL No. G02

\begin{abstract}
$\underline{\text { ABSTRACT }}$
The seemingly never ending scandals in the world of finance with their damaging effects on value and human welfare (that continue unabated in spite of all the various efforts to curtail the behaviorlthat results in those scandals) argues strongly for an addition to the current paradigm of financial economics. We summarize here our new theory of integrity that reveals integrity as a purely positive phenomenon with no normative aspects whatsoever. Adding integrity as a positive phenomenon to the paradigm of financial economics provides actionable access (rather than mere explanation with no access) to the source of the behavior that has resulted in those damaging effects on value and human welfare, thereby significantly reducing that behavior. More generally we argue that this addition to the paradigm of financial economics can create significant increases in economic efficiency and productivity.
\end{abstract}

\author{
Werner Erhard \\ P O Box 31791 \\ Grand Cayman Island KY1-1207 \\ Cayman Islands \\ werhard@ssrn.com \\ Michael C. Jensen \\ 7858 Sanderling Road, \\ Sarasota, FL 34242 \\ and NBER \\ mjensen@hbs.edu
}

An online appendix is available at:

http://www.nber.org/data-appendix/w19986 


\section{INTRODUCTION AND SUMMARY}

\section{a. A Warning and Invitation}

This paper is profoundly different from the way we economists normally model aspects of the world, how we think about measuring the effects of different policy choices on human beings and how we communicate the results of that research.

What we will say about integrity here will stretch most of us. Bear with us since while what we will be saying about integrity will not fit the current worldview or mindset of most economists, if we are successful it will shift your worldview to a more powerful place. What we are discussing is highly relevant to and complementary to economics, business and management, but it is not economics as it is generally thought of and it draws on insights from other disciplines. The roots of what we are dealing with here are in ontology (the philosophy and science of the nature of being) and phenomenology (ontology's methodology). Yet integrity (as we define it) or the lack thereof on the part of individuals or organizations has enormous economic implications (for value, productivity, quality of life, etc.). Indeed, integrity is a factor of production as important as labor, capital, and technology. Without a clear, concise and actionable definition of integrity, economics is far less powerful than it can be. So too finance and management.

We argue here that there are large increases in workability, value, and quality of life to be realized by putting integrity as a positive phenomenon into the theory and practice of finance.

Given the radical departure from the current understanding of what integrity is that is generated by this new model - that is, given the radical departure from the way in which integrity has historically occurred for us - we ask our readers to suspend judgment of the elements until the whole of the model has been laid out.

\section{b. Empirical Evidence}

Up to now, we have not been able to run formal large-scale empirical studies of the impact of integrity on human performance. We are now in the process of formulating and funding large-scale empirical tests that will likely begin in 2015 and run over a number of years. We look forward to the results of these empirical studies. We do, however, have our own experiences with the impact of our model of integrity on our personal and professional lives. In addition, we regularly receive substantial feedback (solicited, unsolicited and non-random) feedback from the instructors and attendees at seminars, programs and courses that include our positive model of integrity. These individuals number in the thousands and range from students to top-level executives and scholars. They consistently report that engaging with integrity as a positive phenomenon has resulted in substantial and productive changes in their overall quality of life, including personal well-being, family and professional lives, and organizational performance.

For an example of the formal measurement of the statistically significant increase in performance see the study of the effect of integrity on student performance outcomes associated with increased student integrity by Isberg, Thundiyil and Owen (2012) 
http://ssrn.com/abstract=2148783 We await the completion of additional formal statistical tests of the impact of our model of integrity.

Paul Fireman, former CEO of Reebok, US, implemented at Reebok an early version of the integrity model discussed here. You might be interested in his assessment of the major impact of that implementation on his and Reebok's remarkable success. See his Commencement Address to the Suffolk University Sawyer Business School on May $19^{\text {th }}, 2013$, Boston, MA. http://www.youtube.com/watch?gl=US\&hl=en\&client=mv-google\&v=ITw0GX4nVXs\&nomobile=1

\section{c. Integrity As We Define It}

In our positive theory of integrity, integrity is defined as: "the state of being whole, complete, unbroken, unimpaired, sound, in perfect condition" - we often refer to this as "whole and complete". This definition (virtually the first two definitions of integrity in Webster's Dictionary) does not define a virtue. There is nothing inherently good, bad or virtuous about being whole, complete, unbroken, unimpaired, sound, in perfect condition. Something just is "whole and complete", or it isn't. We go on to specify what must be whole and complete for 1) an object, or for 2) a system to be in integrity (see Section 3.c, p. 15. And, we specify (see Section 3.d, p. 16) what must be whole and complete for 3) a human being (a person), or for 4) any other human entity (such as a corporation) to be in integrity.

For most people it is obvious that for an object like a bicycle wheel to be whole and complete that bicycle wheel must have all of its parts in working order. We show that the same is true for a system. It is not so obvious (and we explicate this in detail below), that for a person or a human entity (such as a corporation) to be whole and complete that person's or human entity's word must be whole and complete. In our model, a person's word is whole and complete when that person honors his or her word (as we define "honor" and as we define the six components of one's word).

\section{d. Integrity As A Positive Phenomenon}

In our model, we define integrity as a positive phenomenon. As is the case with any positive phenomenon - for example, gravity - there are effects caused by actions related to that phenomenon. The action of stepping off a cliff will, as a result of gravity being a positive phenomenon, cause an effect (whether one likes the effect or not). Likewise, action that is consistent or inconsistent with integrity as a positive phenomenon will also cause an effect (again, whether one likes the effect or not).

When integrity is treated as a positive phenomenon as it is in our model, the relation between integrity, workability and performance is as follows:

1 Maximum workability is a necessary (although not sufficient) condition for maximum performance,

2 Integrity as we distinguish and define it is a necessary and sufficient condition for maximum workability,

3 It follows that integrity is a necessary (although not sufficient) condition for maximum performance, and 
4 It follows that as integrity declines, the opportunity for performance declines.

5 This leads to the empirically refutable proposition that, ceteris paribus, as integrity declines, performance declines.

\section{e. Actual Access To The Source Of Out-Of-Integrity Behavior}

We identify eleven factors that contribute to what we call the "Veil of Invisibility" that hides the actual source of out-of-integrity behavior (see Section 3.h, p. 19 below). Because the actual source of out-of-integrity behavior is almost always hidden, the damaging effects of outof-integrity behavior are attributed to sources other than out-of-integrity behavior - that is, these damaging effects are attributed to false causes. Common examples of false causes that explain the factors that generate the actions that result in these damaging effects are properties inherent in certain individuals or organizations - that is, a person or an organization is immoral, greedy, dishonest, or selfish. While such false causes seem to provide a satisfying explanation for the actions, note that they provide no actionable access to altering the actions. In fact, the almost universal assignment of false causes of the actions that result in these damaging effects actually obscures the real source of those actions. We argue that the real source of those actions is an individual's or organization's word being out of integrity (as we have said, not whole, complete, unbroken, unimpaired, sound, in perfect condition).

\section{DIFFICULTIES WITH THE CURRENT PARADIGM OF FINANCIAL ECONOMICS}

\section{a. An "Obscure Puzzle" in Finance that Calls for a New Paradigm}

There is a continuous and seemingly endless stream of reports of value-destroying behavior by individuals, groups, and organizations in the financial world. For short, we refer to these as "the scandals" (see Appendix 1, p. 47 for a brief summary of what we refer to as "the scandals"). The fact that these scandals keep arising in spite of the ongoing and varied attempts to curtail such behavior amounts to an "obscure puzzle". The persistence of these scandals in spite of all of the efforts to curtail them (a perfect example of what Thomas Kuhn (2012) calls "anomalies and crises" within the prevailing paradigm) is, we argue, strong evidence that the prevailing paradigm of financial economics requires some transformation.

However, as Kuhn (2012, p. 122) points out in The Structure of Scientific Revolutions,

Paradigms are not corrigible [changeable] by normal science at all. ... normal science ultimately leads only to the recognition of anomalies and to crises [within the prevailing paradigm].

To resolve the "anomalies and crises" of the seemingly unstoppable scandals in the financial world, we propose an addition to the generally accepted financial economics paradigm. This addition to the prevailing paradigm opens up a perspective that reveals the actual source of these scandals, and explains why the best efforts of regulatory agencies, the legal authorities, the media, etc., etc. have so far failed to stem the tide. Our proposed addition to the financial economics paradigm reveals actionable opportunities for effectively dealing with the actual source of the continuing stream of value-destroying behavior by individuals, groups, and organizations in the world of finance. 
Given that we are proposing a change to a prevailing paradigm, much of what we present in this paper is outside the accepted boundaries of the current paradigm of financial economics. So in the spirit of full disclosure, we caution our readers that we will be introducing terms, perspectives, and ideas that may at first seem strange, and some that will be familiar but are used here in an unusual way. Moreover, when viewed from within the confines of the current paradigm what is being dealt with in this paper may seem irrelevant or just plain wrong, or simply inappropriate and not to be dealt with in a financial economics journal.

For example, to start with, finance and economics scholars tend to avoid discussions or considerations of "integrity" because integrity is for them normative (occurs for them as normative). That normative presumption makes it challenging to even begin to consider integrity constituted as a purely positive phenomenon as it is in this paper. Kuhn (1996, p. 122) comments on the challenge of introducing a new paradigm (and we would argue adding to an established paradigm):

“... normal science, an enterprise that, as we have already seen, aims to refine, extend, and articulate a paradigm that is already in existence. ... But that interpretive enterprise [normal science] ... can only articulate a paradigm, not correct it. Paradigms are not corrigible by normal science at all."

By the way, should you begin to see some value in our model, because it is simply impossible to be complete in one paper on the huge topic dealt with here, you will certainly have questions and challenges regarding certain specifics that we will not have addressed or at least have not fully addressed. ${ }^{2}$ By the same token, we will have established a new perspective from which to view the source of these scandals. When these scandals are viewed from this new perspective one sees possibilities for effectively dealing with them - possibilities that were not apparent from the current perspective on these scandals.

In any case, we ask our readers to keep an open mind - that is, willingly suspend the immediate need to accept or reject what is presented until it is fully presented - and then to fully "try on" this new perspective to determine if from within this perspective there is a new possibility that promotes value-enhancing behavior by individuals, groups, and organizations. We rely on Thomas Kuhn (p. 122) as follows for the foundation for making this request. Kuhn, speaking about what is possible from within a new perspective, concludes,

“... these ["anomalies and crises"] are terminated, not by deliberation and interpretation, but by a relatively sudden and unstructured event like the gestalt switch."

In Kuhn's (p. 122) attempt to make clear what he means by "gestalt switch", he says,

"Scientists then often speak of the 'scales falling from the eyes' or of the 'lightning flash' that 'inundates' a previously obscure puzzle, enabling its components to be seen in a new way that for the first time permits its solution." [italics and underlining added]

The basis for 1) our proposal to add to the generally accepted financial economics paradigm, and the basis for 2) our request to our readers to try on seeing a problem and therefore its solution in an unfamiliar new way is our desire to (quoting Kuhn) "inundate a previously

$2 \quad$ We are in the process of drafting a more complete treatment of our positive theory of integrity in our book, with the working title "A Positive Theory of the Normative Virtues", to be published by Cambridge University Press. 
obscure puzzle, enabling its components to be seen in a new way that for the first time permits its solution”.

\section{b. Behavioral Economics and Behavioral Finance: Providing Explanations Rather Than Providing Access To Altering Human Behavior}

The progress in economics and finance over the last two-plus decades - founded on the paradigm-altering insights from psychology about human behavior by scholars such as Kahneman, Tversky, Thaler, Sunstein and others - has been huge. This paradigmatic revolution has allowed the profession to focus on the existence and significant impact of widespread counter-to-self-interest behavior that was heretofore unnoticed. Until Kahneman and Tversky's (1979) Econometrica paper "Prospect Theory: An Analysis of Decision under Risk", such counter-to-self-interest behavior was in a sense invisible when viewed through the lens of the prevailing rational/self-interest theory/paradigm. Or, that behavior was simply dismissed as irrational and therefore an irrelevant anomaly (consistent with what Kuhn (1996, pp. 111-135) termed "theory-dependence of observation"3 in his chapter "Revolutions as Changes of World View). Indeed, behavioral economics and behavioral finance have now become major areas of research on their own. The insights in these areas flow from our finally recognizing that there is something about us human beings such that we often behave in ways that are contrary to our self-interest (unfortunately still often explained away as "irrational behavior").

The contributions from behavioral economics and behavioral finance have been extraordinarily powerful in providing explanations for the widespread existence of counter-toself-interest behavior. However, as powerful as these contributions have been in explaining this behavior, they have been much less successful in providing access to altering human behavior. Here we are highlighting the contrast between a model that explains a category of behavior, and a model of that same category of behavior that provides actionable access to altering the behavior.

Kahneman (2011, p. 417) himself acknowledges that even clear explanations for a certain category of behavior do not lead to altering that behavior. In this case, the explanations are "biases" and the category of behavior is so-called "irrational" behavior. As Kahneman says:

"What can be done about biases? ... The short answer is that little can be achieved without a considerable investment of effort." (p. 417)

Speaking about his own personal experience of the lack of impact of even considerable knowledge about what explains our so-called "irrational behavior", Kahneman continues:

"Except for some effects that I attribute mostly to age, my intuitive thinking is just as prone to overconfidence, extreme predictions, and the planning fallacy as it was before I made a study of these issues." ${ }^{4}$ (p. 417)

3 See Bird (2011) Stanford Encyclopedia of Philosophy entry "4.2 Perception, Observational incommensurability, and World-Change": http://plato.stanford.edu/archives/win2011/entries/thomaskuhn/

4 In his review of Kahneman's book Thinking, Fast and Slow, theoretical physicist and mathematician Freeman Dyson (2011) reflecting on Kahneman's thinking about this phenomenon says: 
Kahneman's statements, and the need to resort to nudging (see directly below), lead one to conclude that even powerful explanations for behavior do not necessarily provide any powerful access to altering that behavior. At least this is the case with the biases of intuition and simplifying heuristics that explain counter-to-self-interest behavior.

To deal with the problem that explanations do not alter behavior, Thaler and Sunstein (2008) in their book Nudge provide a workaround for this problem. They argue persuasively that people can be directed (nudged) into acting in their own self-interest. Nudging accomplishes this by avoiding the requirement to make a decision between the alternatives. And avoiding the requirement to make a decision is a way to work around the biases of intuition and simplifying heuristics that are triggered when one must make a decision. For the most part, nudging avoids the requirement to decide between alternatives by presenting the alternatives with a default condition. Nudging nudges people into acting in the way those who structure what is being dealt with conclude is in the person's, group's, or organization's own self-interest. ${ }^{5}$

However, nudging is not a resolution of the problem of altering the counter-to-selfinterest behavior associated with biases and heuristics. By providing the no-need-to-choose default selection, nudging removes the necessity for the nudgee to make a decision. And, removing the requirement to decide, removes the impact on behavior of biases and heuristics (which are triggered when confronted with a decision). Again, this is a workaround.

As Thaler and Sunstein acknowledge (see Chapter 17, p. 235), nudging is paternalistic (in their words, "libertarian paternalism"), but as they also acknowledge, when employed by the unscrupulous, nudging can be downright manipulative and used to exploit people.

By contrast, unconcealing the actual nature of integrity (which happens as the result of the new way we model integrity) makes present in real time the relation between a certain behavior (in this case, acting with integrity or not) and the consequences of such behavior (in this case, on value or more generally on workability and the opportunity for performance). In other words, this new model of integrity not only reveals the counter-to-self-interest impact on an individual, group, or organization that results from out-of-integrity behavior, it does so such that acting without integrity occurs for a person along with the undesirable impact on value and performance. In short, acting with integrity or the lack of it, and the resulting desirable or undesirable impact on value and performance, arise together. It is critical to note that when an out-of-integrity action occurs to (shows up for) an individual, group, or organization (or even for you or me) as counter to its self-interest, the likelihood of acting in that way is significantly diminished.

While we will explicate more fully what we mean by "occur", an oversimplified example of what we mean by "occur" shows up in the following: The way something is understood by us or seems to be for us is a result of the way we frame it. Consequently, change your frame for something and the way you understand it and the way it seems to be for you will change - that is, the way in which it occurs for you will change.

\footnotetext{
"We also know that, even when we become aware of the bias and the illusions, the illusions do not disappear. What use is it to know that we are deluded, if the knowledge does not dispel the delusions?"

$5 \quad$ For a series of experimentally-based effective persuasion techniques, see Goldstein, Martin and Cialdini (2007).
} 
This is in sharp contrast with the way biases of intuition and simplifying heuristics function, where at the time of the behavior that results from these biases and heuristics the damaging impact on one's self interest is obscured. In fact, at the time, it actually appears to the person that the resultant behavior is in their self interest. It is only from a third-person perspective that the behavior that results from biases and heuristics is seen as counter to one's self interest. And this includes the person, group, or organization themselves when later they have the distance for a third-person perspective on their earlier behavior. It is important to keep in mind, that even the knowledge that biases of intuition and simplifying heuristics will result in actions that are counter to self interest does not impact people's behavior. And, this includes even people with the knowledge and experience of Daniel Kahneman (as he himself acknowledges in the above quotes).

Rather than an explanation for the behavior, this new model of integrity makes present the consequences of the behavior at the time of deciding how to behave. And, when the consequences of this or that behavior are palpably present in making a decision about how to behave, one is more likely to behave in one's actual self-interest.

In addition, our new model of integrity reveals exactly what constitutes out-of-integrity behavior. And that contrasts dramatically with the way in which integrity currently occurs for people wherein a great deal of out-of-integrity behavior does not even occur as out-of-integrity. This shift in the way out-of-integrity behavior occurs to an individual, group, or organization (in fact so that it occurs as out-of-integrity behavior, and at the same time it occurs as counter to its own self-interest) is the access this new model of integrity provides to altering behavior.

\section{c. The Counterproductive Effects of the Term "Irrational Behavior"}

There is no doubt that the twenty or so biases of intuition and simplifying heuristics described by Kahneman and Tversky cogently explain what is termed "irrational behavior". While we have no argument with the accuracy of the explanations, we argue that the counter-toself-interest behavior is identified as "irrational behavior" because it was researched within the context of the rational-mind paradigm of psychology, and within the utility-maximizing individuals acting in perfect markets (people acting in their own self-interest) paradigm of economics. Unfortunately, labeling the behavior irrational, while explaining the behavior perfectly, obscures the source of that behavior. Moreover, using irrational to counter or contrast with rational elicits an analysis not of the observed behavior but an explanation of its presumed irrationality.

In fact, assuming that the behavior associated with the biases and heuristics identified by Kahneman and Tversky is irrational obscures something critically important about the impact of those biases and heuristics. A person with a normal brain acts in what appears to that person (to that person's brain) to be in his or her self interest. That is, a person acts in what appears to be their self-interest given the way in which what they are dealing with or are confronted with occurs or shows up for them. ${ }^{6}$ Saying the same thing in another way, given the way what we are dealing with or confronted with occurs for us, we make what appear to be rational choices given that occurring. While as we said above, from a third-person perspective (and even for the person

6 Erhard, Jensen, and Barbados Group, "A New Paradigm of Individual, Group, and Organizational Performance" (2010). Available at SSRN: http://ssrn.com/abstract=1437027 
themselves when later they have the distance for a third-person perspective on their earlier action), the action that at the time appeared to be in a person's self-interest may in fact prove to be counter to their self interest. ${ }^{7}$

We argue that the biases and heuristics described by Kahneman and Tversky do more than merely explain counter-to-self-interest behavior. We argue that those biases and heuristics actually alter the way in which what-a-person-is-dealing-with occurs for that person. And in the occurring altered by those biases and heuristics, the action that subjectively appears to be in one's self interest (the apparent rational choice) is in fact objectively counter to one's self interest. In summary, given the impact of those biases and heuristics on the way what-a-personis-dealing-with occurs for that person, the objectively counter-to-self-interest behavior subjectively appears perfectly rational.

As a consequence of the foregoing, we strongly prefer "counter-to-self-interest behavior" over "irrational behavior". As Kahneman himself declares:

"Like most protagonists in debates, I have few memories of having changed my mind under adversarial pressure, but I have certainly learned more than I know. For example, I am now quick to reject any description of our work as demonstrating human irrationality. When the occasion arises, I carefully explain that research on heuristics and biases only refutes an unrealistic conception of rationality, which identifies it as comprehensive coherence. Was I always so careful? Probably not." 8

Carefully examining every dumb act in our own lives it is clear that each seemed like "a good idea at the time", i.e., desirable and perfectly rational in that the costs were less than the benefits given the way in which what we were dealing with occurred for us at the time. What made the act dumb was not irrationality, rather it was the way Kahneman and Tversky's biases and heuristics caused what we were dealing with to occur or show up for us.

By labeling the behavior "irrational", we scholars end up skewing our research to find the source of irrationality, rather than to find the source of the behavior. So the use of that label gave people an answer (that it was irrational) before they did the careful looking to actually see the behavior. If what we have to explain is irrational behavior, we are now not looking for what causes the behavior, we are looking for what causes the irrationality.

The fact that I am likely to apply a bias or heuristic to what I am dealing with (a fact made available by Kahneman, Tversky and others) can be understood in one of two ways. It can be framed 1) as leaving me acting irrationally, or it can be framed 2) as distorting the way in which what I am dealing with occurs or shows up for me.

When biases or heuristics are framed as leaving me acting irrationally, I am left with no awareness of, and consequently no access to dealing with, the distortion from the bias or heuristic on the way what I am dealing with occurs or shows up for me. And, as a consequence

$7 \quad$ For an extended discussion of the proposition that action is a correlate of the way in which what one is dealing with or is confronted with, see Erhard, Jensen, and Barbados Group, A New Paradigm of Individual, Group, and Organizational Performance (2010). Available at SSRN: http://ssrn.com/abstract=1437027

$8 \quad$ Kahneman, Daniel, "Nobel Prize Autobiography", accessed March 4, 2012 http://www.nobelprize.org/nobel_prizes/economics/laureates/2002/kahneman-autobio.html 
my actions will be a correlate of the distorted way in which what I am dealing with occurs for me. Such actions are more likely to be contrary to my self-interest.

As we said, Kahneman himself says,

"What can be done about biases? ... Except for some effects that I attribute mostly to age, my intuitive thinking is just as prone to overconfidence, extreme predictions, and the planning fallacy as it was before I made a study of these issues." 9 (p. 417)

\section{d. Out-of-Integrity Behavior: The Unnoticed Elephant in the Living Room of Behavioral Puzzles}

Our focus in this paper is integrity - that is, what is discovered when integrity is revealed as a positive phenomenon (as it is in our new model of integrity).

Given the pervasive understanding of integrity as a normative phenomenon - which makes seeing the function and consequences of integrity as a positive phenomenon very difficult - in this section we ask forgiveness for being a bit laborious in our explication of the function and consequences of integrity as a positive phenomenon.

In spite of the enormous damaging impact on human welfare from out-of-integrity behavior, the universal prevalence of out-of-integrity behavior has gone unnoticed in the behavioral literature that has evolved in the last 30 years. This, even though out-of-integrity behavior (while generally not recognized as such) is in fact a significant portion of all counter-toself-interest behavior. By the way, the damage from such behavior that makes the headlines is a small portion of the actual total damage from out-of-integrity behavior.

The widespread damage to human welfare caused by out-of-integrity behavior is not identified as being caused by out-of-integrity behavior. This is the result of most out-of-integrity behavior not being recognized as actually being out-of-integrity. Consequently, a good deal of the enormous costs to individuals, groups, and organizations that actually result from out-ofintegrity behavior are mistakenly explained as coming from other causes. Thus, all of us engaging in this explanatory behavior short-circuit the search for the actual source of the damage.

In addition, even when an individual, group, or organization's out-of-integrity behavior shows up for them as out-of-integrity behavior, it often occurs as damaging to others and not to the individual, group, or organization that is engaging in such behavior - at least not damaging to them as long as they "don't get caught" or will at least "get away with it". No matter how great or small the damage to others from one's out-of-integrity behavior, one's out-of-integrity behavior is as we will show is always damaging to oneself. In speaking about the "enormous costs" resulting from out-of-integrity behavior we are not speaking merely about the consequences of getting caught. As we will show, even when we "don't get caught" or we "get away with it", the costs to ourselves of out-of-integrity behavior are enormous.

9 In his review of Kahneman's book Thinking, Fast and Slow, theoretical physicist and mathematician Freeman Dyson (2011) reflecting on Kahneman's thinking about this phenomenon says: "We also know that, even when we become aware of the bias and the illusions, the illusions do not disappear. What use is it to know that we are deluded, if the knowledge does not dispel the delusions?" 
We demonstrate that a powerful opportunity to support people, groups and organizations to act in their own self-interest begins (but only begins) with the recognition that as we have said each of us (individuals, groups, and organizations) inflicts enormous damage on ourselves and others as a result of our widespread and systematic out-of-integrity behavior. However, as $a$ consequence of the way integrity is currently understood (currently occurs or shows up for people), again, as we have said much out-of-integrity behavior is not recognized by people, groups, and organizations as being out of integrity. As a consequence, for the most part, people, groups, and organizations do not recognize that the damage inflicted on themselves and others from their out-of-integrity behavior is in fact a result of their own out-of-integrity behavior.

What integrity actually is, and the way integrity functions and the consequences of the way it functions, is misidentified by virtually all people, and as a result they explain the damage as coming from some cause other than their out-of-integrity behavior, or they explain away the damage as, "that's just a part of the way people, life, business, or the world is". As a result of this misidentification, just what integrity is, as well as what it is to act with integrity or act without integrity, and the consequences of either type of action, is for all practical purposes invisible.

Summarizing the foregoing: dealing effectively with out-of-integrity behavior begins with a clear recognition of the following four facts regarding integrity, which recognition the model of integrity introduced in this paper makes available:

1) Just how widespread out-of-integrity behavior actually is, and

2) the enormity of the cost of out-of-integrity behavior.

3) Given the way integrity is currently understood, our out-of-integrity behavior does not occur for us as such, and as a result

4) we ascribe the cause of the damage from our out-of-integrity behavior to something other than our out-of-integrity behavior.

These four facts are only a beginning because, as is the case with the counter-to-selfinterest behavior explained by the biases and heuristics identified by Kahneman, Tversky and others, the knowledge of such information by itself does little to alter behavior. What else is required to provide a powerful opportunity for people, groups and organizations to act in their own self-interest with regard to integrity?

Integrity must occur (be understood and show up) for people, groups and organizations in a radical new way. Integrity must occur for people, groups and organizations such that:

1) Out-of-integrity behavior actually shows up for them as being out-of-integrity, and

2) The damaging consequences of that behavior, whether immediate or long term, show up for them in present time right along with the behavior, and

3) Those damaging consequences show up for them as being caused by the out-ofintegrity behavior.

When people, groups and organizations see integrity through the lens of this new model, 1), 2), and 3) are realized naturally. To be clear, from within this new model of integrity, integrity occurs for people (is understood by people, shows up for people) such that 1) out-of- 
integrity behavior actually shows up for people as out-of-integrity behavior, but most importantly, 2) the damaging consequences of that behavior, whether immediate or long term, show up in present time right along with the behavior, and finally 3) the damaging consequences show up as being caused by the behavior.

As we said above in Section 1.c, people with normal brains act in what appears to them to be in their self interest, but in their self interest given the way in which what they are dealing with occurs or shows up for them. The way in which integrity is currently understood often makes what one is dealing with occur such that out-of-integrity behavior actually appears to be in one's self interest, or the behavior is not even recognized as being out of integrity.

If out-of-integrity behavior shows up for me as actually being out-of-integrity, and if the damaging consequences of out-of-integrity behavior show up for me in present time right along with the behavior, and if those damaging consequences show up as being caused by out-ofintegrity behavior, it is obvious that I am less likely to behave out-of-integrity. (Speaking about this in another way, our brains evolved to generate reward-resulting behavior and avoid punishment-resulting behavior, but the behavior the brain does generate, it generates given the way in which our perception of what we are dealing with occurs in our brain.)

Summarizing fully what we have said is required in addition to a clarity about the four facts listed above in this section: the actual source of people, groups, and organizations acting out of integrity and ascribing the resultant damage to causes other than acting out of integrity is a product of the way in which integrity is currently "understood" - that is, is a product of the way in which integrity currently occurs for people. In short, what we mean by "understood" is people's understanding of what for an object, system, person, or other human entity constitutes being in or out of integrity, and the consequences that result from being in or out of integrity. More precisely, what we mean by "the way in which integrity is currently understood" is the way in which integrity as a phenomenon currently occurs for people. Just what acting with integrity and acting without integrity actually is depends on the way integrity as a phenomenon occurs for people. Finally, our awareness of what the real damage is from out-of-integrity behavior and what the benefits are from acting with integrity also depends on the way integrity as a phenomenon occurs for people.

In the next Section we summarize our purely positive model of integrity (not to be confused or conflated with the normative phenomena of morality, ethics, or character). This forms the foundation for our main task in this paper: analyze the many ways in which finance can be dramatically improved by putting a model of integrity as a positive phenomenon into the theory and practice of finance.

We will first reveal integrity as a positive phenomenon, and as a positive phenomenon what integrity is for objects and systems, and what integrity is for persons and other human entities. We then discus the consequences of behaving consistent with and inconsistent with the nature of integrity as a positive phenomenon, and the consequences of each kind of behavior to self interest. We go on to discuss what has gotten in the way of seeing integrity as a positive phenomenon (what we call the "veil of invisibility"). This inability to see integrity as a positive phenomenon results in misidentifying out-of-integrity behavior as something other than out-ofintegrity behavior. And, this in turn results in misidentifying the cause of many counter-to-selfinterest outcomes. 


\section{A PURELY POSITIVE MODEL OF INTEGRITY}

It took economics over 100 years to wake up to the fact that the presumption of selfinterest was flawed, even though the counter-to-self-interest behavior was right in front of us all those years. The breakthrough in behavioral economics in large measure rewrites the economic script for analyzing human behavior. In this paper we argue that the longstanding naive presumption of self-interest is parallel to the total lack of recognition that integrity is a factor of production that is as important to success in all aspects of life as knowledge, technology and human and physical capital - and that importance has been invisible to us even though it is in plain sight. Integrity as a factor of production is undistinguished and therefore unmanaged - and as we said, its actual impact on life is huge. We have been involved in this research into a purely positive theory of integrity since 2004 and the work is as yet incomplete. ${ }^{10}$

The way integrity has been historically framed and as a consequence the way in which integrity occurs for people obscures the powerful impact of integrity on the functioning of the world and on life, for every human being and human entity. Resolving this issue so that the impact of integrity becomes easily visible has required us to establish a new conversational domain for integrity, morality, ethics, and legality. This conversational domain retains the primal and fundamental meaning of each of these concepts as expressed in their dictionary definitions, but clarifies the definitions and makes each term distinct from the other by eliminating the mischief of the ambiguity and confounding of their overlapping definitions. ${ }^{11}$ Unfortunately most people resist the creation of a new conversational domain because by definition it is unfamiliar to them, and the reaction often is "Don't use all these new words and concepts, just use the plain English of the domain I am an expert in (say economics)". This is equivalent to a first-yearstudent of mathematics saying to the teacher: "Don't use all these strange terms to communicate mathematics to me (like calculus or number theory), just use plain English", and similarly with someone dealing with medicine, engineering or physics. Obviously that will not work because it is the conversational domain of each of these areas that provides access to being a master of the discipline.

10 See the following for extended discussions of this work, much of which deal with the modeling issues in more detail than we have room for in this paper. Some chapters from our forthcoming book to be published by Cambridge University Press are contained in, Erhard, Werner and Jensen, Michael C., A Positive Theory of the Normative Virtues (December 7, 2011). Harvard Business School NOM Unit Working Paper No. 12-007; Barbados Group Working Paper No. 11-06. Available at SSRN: http://ssrn.com/abstract=1906328 and our earlier papers: Erhard, Werner, Jensen, Michael C. and Zaffron, Steve, Integrity: A Positive Model that Incorporates the Normative Phenomena of Morality, Ethics and Legality (March 23, 2009). Harvard Business School NOM Working Paper No. 06-11; Barbados Group Working Paper No. 06-03; Simon School Working Paper No. FR 08-05. Available at SSRN: http://ssrn.com/abstract=920625 or Erhard, Werner, Jensen, Michael C. and Zaffron, Steve, Integrity: A Positive Model that Incorporates the Normative Phenomena of Morality, Ethics, and Legality - Abridged (English Language Version) (March 7, 2010). Harvard Business School NOM Unit Working Paper No. 10061; Barbados Group Working Paper No. 10-01; Simon School Working Paper No. 10-07. Available at SSRN: http://ssrn.com/abstract=1542759 and Jensen, Michael C. and Erhard, Werner, A 'Value-Free' Approach to Values (PDF File of Powerpoint Slides) (April 11, 2011). Harvard Business School NOM Unit Working Paper No. 11-010; Barbados Group Working Paper No. 10-06; Simon School Working Paper No. FR10-26. Available at SSRN: http://ssrn.com/abstract $=1640302$

11 See Erhard and Jensen (2011, Chapter 1) http://ssrn.com/abstract=1906328 
Our purpose here is to summarize our new model of integrity, introduce its required new terminology, and deal with the actual effects of integrity in life, with particular focus on corporate, market, personal and policy issues in finance, governance and compensation.

\section{a. Integrity: Definition}

We start with the dictionary definition of integrity using Webster's New World Dictionary (1998):

1. the quality or state of being complete; unbroken condition; wholeness; entirety

2. the quality or state of being unimpaired; [in] perfect condition; soundness

3. the quality or state of being of sound moral principle; uprightness, honesty, and sincerity

We use the word "integrity" in this work following Webster's definitions 1 and 2. Note that those two definitions define a purely positive phenomenon with no normative content. As we distinguish and use the word "integrity", we do not include Webster's definition 3. That is, we do not use "integrity" to refer to the normative concepts of "being of sound moral principle; uprightness, honesty, and sincerity", or to refer to an ethical or moral code or standard, or to denote anything about right vs. wrong, good vs. bad, or desirable vs. undesirable. Note that using "moral" in the definition of integrity confuses and confounds the meaning of each.

What follows are the rigorous definition of integrity, the relation between integrity and workability, the relation between workability and performance, the relation between integrity and performance, the law of integrity, and the relation between integrity and value, derived in our in-process book "A Positive Theory of the Normative Virtues" Erhard and Jensen (2011, Chs. 1, 2 and 3). These are some of the fundamental terms that make up this new conversational domain that gives us access to integrity and its impact on the world.

- Integrity Defined: For an object, system, person, or other human entity or practice, the state of being whole, complete, unbroken, unimpaired, sound, in perfect condition.

- The Relation between Integrity and Workability: Integrity (the state of being whole, complete, unbroken, unimpaired, sound, in perfect condition) is the necessary and sufficient condition for maximum workability (capable of producing the desired effect or result). ${ }^{12}$

- The Relation between Workability and Performance: Workability (capable of producing the desired effect or result) is a necessary but not sufficient condition for performance (however one wishes to define performance).

12 The New Oxford American Dictionary (2010) defines workable as "capable of producing the desired effect or result ..." Workability (the noun form of workable, the definition of which is derived from the adjectival form of the word) denotes the degree to which something is capable of producing the desired effect or result, ranging from no opportunity for producing the desired effect or result to the maximum opportunity for producing the desired effect or result. 
- The Relation between Integrity and Performance: Integrity (the state of being whole, complete, unbroken, unimpaired, sound, in perfect condition) is thus a necessary but not sufficient condition for performance.

- The Law of Integrity: As the integrity (the state of being whole and complete, etc.) of an object, system, person, or other human entity or practice declines, workability declines, and as workability declines the opportunity for performance declines.

- The Relation between Integrity and Value: Integrity is therefore a necessary but not sufficient condition for long-run value maximization.

\section{b. The Long-Neglected Positive Role of Integrity in Finance and Economics}

As we have said, finance and economics scholars tend to avoid discussions or considerations of integrity because it has occurred to them as "normative". However, integrity as we have defined it in this new model is a purely positive phenomenon. For any object, system, human entity, or human practice, integrity (as we distinguish it for each of these four) is observable. That is, an object, system, human entity, or human practice is either observably whole, complete, unbroken, unimpaired, sound, in perfect condition, or it is not. Furthermore, it is an inescapable conclusion that as whole and complete, etc. declines, workability declines. And, as workability (capable of producing the desired effect or result) declines the opportunity for performance declines (however one wishes to define performance). Hence, the effect of integrity on the opportunity for performance, including value, productivity, quality of life (and the like), is a purely positive proposition.

Our posited link between integrity and workability (and consequently, value) is no more normative than the posited link between the traditional net present value rule for investment decisions and corporate value. "Long-run value maximization requires integrity" is a positive proposition that is testable and refutable. And the empirical effects of integrity or its absence have too long been ignored in finance and economics.

In our framework, as we have said, integrity is a necessary but not sufficient condition for long-run value maximization. For example, if you have integrity and thus a large opportunity for performance, but you are committed to only a small game in life (for example: I will get up in the morning) then you are not likely to create anything of value, in spite of having integrity. In fact for an organization to create maximum value, it must also create and execute brilliant competitive, organizational, technological, and human strategies in addition to integrity.

\section{c. Integrity for an Object or System}

An object or system has integrity when it is whole and complete. An object without integrity doesn't work. Think of a wheel with missing spokes, it is not whole and complete, and therefore is not stable. It will become out-of-round, work less well and eventually stop working entirely.

For an object or system to be in integrity it must satisfy the following conditions: 
1. The Design must be in integrity - that is, the design must be whole, complete, unbroken, sound, in perfect condition. Specifically, the design when executed must be capable of producing the intended result or performance ${ }^{13}$ ).

2. The Implementation of the design must be in integrity - that is, the implementation of the design must be whole, complete, unbroken, sound, in perfect condition. Specifically, the implementation of the design must in fact realize the object or system as designed.

3. The Use of the implemented object or system must be in integrity - that is, the use of it must be whole, complete, unbroken, sound, in perfect condition. Specifically, the use of the object or system must be allowed by its design and be consistent with its designed purpose.

- For example, a 200-pound man using a life vest designed for a 50-pound child will drown unless he can swim.

By the way, the foregoing also applies to the integrity of a human system as a system.

\section{d. Integrity for a Person or other Human Entity (family, group, organization, society, and nation)}

Integrity for a person or other human entity is a matter of that person's or entity's word nothing more and nothing less.

In the matter of integrity (being whole, complete, etc.) it is not too much to say that a person or other human entity is their word - that is, is constituted by their word. It follows that when a person's or other human entity's word is less than whole, complete, unbroken, sound, in perfect condition, that person as a person or that entity as a human entity is less than whole, complete, unbroken, sound, in perfect condition. This results in the person or entity as less workable, and therefore with a diminished opportunity for performance. Conversely, it also follows that when a person's or other human entity's word is whole, complete, unbroken, sound, in perfect condition, that person as a person and that entity as a human entity is whole, complete, unbroken, sound, in perfect condition. This results in the person as a person or human entity as a human entity being fully workable, and therefore with a maximum opportunity for performance.

For a person or other human entity to be in integrity they must satisfy the following conditions:

13 "Intended result or performance" includes all aspects of the results or performance of an object or system, including all relevant concerns in the design, implementation, and use of that object or system; for a few obvious examples, construction, operating, and maintenance costs, as well as durability and all relevant aesthetic requirements. 
1. The person's or other human entity's word must be whole, complete, unbroken, sound, in perfect condition.

2. For the word of a person or other human entity to be whole, complete, unbroken, sound, in perfect condition, they must keep their word, or when they will not be keeping their word, they must maintain their word as whole, complete, etc. by honoring their word.

\section{e. Integrity: Keeping or Honoring One's Word}

1. Briefly summarized a person's or other human entity's word includes the following (see the Online Appendix at: http://www.nber.org/data-appendix/w19986/ for a precise and complete definition of what we mean by each of the following 6 aspects of one's word);

- Word-1: What you said you would do or not do

- Word-2: What you know to do or not to do

- Word-3: What is expected of you by those with whom you desire a workable relationship (that is, their expectations that are in fact unexpressed requests of you), unless you have specifically declined this or that of those expectations

- Word-4: What you say is so (your evidence for what you say is so, would satisfy your listener)

- Word-5: What you stand for

- Word-6: Moral, Ethical and Legal Standards

- The social moral standards, the group ethical standards and the governmental legal standards of right and wrong, good and bad behavior, in the society, groups and state in which one enjoys the benefits of membership are also part of one's word (what one is expected to do) unless a) one has explicitly and publicly expressed an intention to not keep one or more of these standards, and b) one is willing to bear the costs of refusing to conform to these standards (the rules of the game one is in).

2. For a person or other human entity, keeping your word means you fulfill your commitments and promises in full and on time.

However, if you always keep your commitments and promises you are undoubtedly not playing a big enough game in life. For example, as we suggested above, you might commit to nothing more than that you will wake up each morning. While you will only fail at that once, you will certainly be playing a small game in life.

3. For a person or other human entity, honoring your word means that you either:

- Keep your commitments and promises, and on time, or 
- When you have failed (or expect to fail) to keep a commitment or promise on time, you honor your word by:

○ Acknowledging that failure as soon as you realize it, and saying by when you will now keep that word, or that you never will keep that word, and

- Cleaning up any mess you created for those who were counting on you to keep your word (your commitments and promises) on time.

For a person or other human entity, honoring your word means that you are honest and straightforward: This means nothing is hidden, no deception, no untruths, no violation of contracts or property rights, etc. And (as explained above) because your word also includes conforming to the rules of the games you are in (for example, ethical standards of the profession or organization you are in, and the moral standards of the society and legal standards of the government entity you are in). If you refuse to play by any of the rules of the games you are in, integrity requires you to make this refusal clear to all others and to willingly bear the costs of doing so. (Gandhi is an example.)

As we have indicated, all this applies not only to a person, but to a human organization (such as a university, partnership or corporation) as well. As we define integrity, an organization or any other human entity is in integrity when it's word is whole and complete. This means it honors its word, both to its employees and to its customers, suppliers and other stakeholders. Again, this means nothing is hidden, no deception, no untruths, no violation of contracts or property rights, etc. And if the organization or other human entity refuses to play by any of the rules of the game it is in, integrity requires it to make this clear to all others and to willingly bear the costs of not playing by one or more of the rules of the game.

\section{f. Workability: The Bridge between Integrity and Value Creation}

The more a person or other human entity is out of integrity (the less whole, complete, etc. their word is), the smaller their opportunity for performance. This, is a result of the decline in workability. Put simply (and somewhat overstated):

- "Without integrity nothing works."

We use this as a heuristic. Put more rigorously:

As integrity (whole and complete) declines, workability (capable of producing the desired effect or result) declines, and as workability declines, the opportunity for performance declines (however one chooses to define performance). Thus, value maximization requires integrity.

\section{g. An Example of the foregoing: Results from Applying these Principles of Integrity at SSRN}

The above definitions of integrity (including the three simple aspects of the definition of integrity for objects and systems) have provided enormous power at SSRN (http://ssrn.com) where Michael (a co-author of this paper and Integrity Officer at SSRN ${ }^{14}$ ) has used them in

14 In the spirit of full disclosure, Michael is also cofounder and Chairman of the Board of SSRN. 
bringing about a culture of integrity that has produced major increases in productivity. Bringing about increases in the integrity of SSRN's staff as individuals (including himself) and in the integrity of SSRN both as an organizational system and as a human entity enabled increases in productivity at SSRN of 300\% over the first three years of SSRN's efforts in this domain. Interestingly those productivity increases have also been associated with substantial increases in the satisfaction and happiness of SSRN's staff. SSRN has also experienced large increases in productivity as ITX (http://www.itx.com/), SSRN's outside vendor of web technology services, learned about integrity through its interaction with SSRN and adopted integrity (as distinguished in this paper) as a major element of its own organizational strategy. It is worth contemplating how it could have been that such huge increases in productivity were lying around without being noticed - another important example of counter-to-self-interest behavior that was invisible in the way the world occurred to the relevant parties at both SSRN and ITX. The size of the increases in productivity reported here may tempt some of our readers to dismiss them. Howerver, you should know that SSRN's productivity has continued to increase subsequent to these first three years.

\section{h. The "Veil of Invisibility"}

Given the significant contribution to performance and quality-of-life that we discovered from acting consistent with the Law of Integrity, and conversely the devastating impact on performance from violating the Law of Integrity, ${ }^{15}$ we were dumbfounded that the actual source of these benefits and costs has remained invisible. Faced with that puzzle, we spent two years focused on determining what created that invisibility.

We discovered eleven distinct factors that create what we call the Veil of Invisibility ${ }^{16}$ that for human beings and other human entities makes invisible the impact of integrity on their opportunity for performance. Each of these eleven factors contributes to obscuring for human beings and other human entities the negative impact on performance when their actions are inconsistent with the Law of Integrity, and conversely obscures the positive impact on performance when their actions are consistent with the Law of Integrity.

Ignorance of the Law of Integrity, kept in place by the eleven factors of the Veil of Invisibility, prevents us from seeing the actual source of the devastating impact that out-ofintegrity behavior has on our lives, and the lives of our families, groups, organizations, societies, and nations. Furthermore, ignorance of the Law of Integrity and of its relation to performance leads to explanations for poor performance that, while seemingly valid, hide the actual cause of that performance. Diagnosis of less than desirable performance and prescriptions for addressing that diagnosis that are not informed by the Law of Integrity are generally unreliable and often downright ineffective in providing an effective pathway for resolving performance issues. Some evidence for this is the media reports of the unrelenting "scandals" we have mentioned.

For now we provide a brief listing and description of the eleven factors of the veil of invisibility that prevent us human beings from seeing and therefore accessing the power that

15 "As the integrity (the state of being whole and complete, etc.) of an object, system, person, or other human entity or practice declines, workability declines, and as workability declines the opportunity for performance declines."

16 Playing on Harsanyi $(1953,1955)$ and Rawls $(1971,2001)$ "Veil of Ignorance". 
acting consistent with the Law of Integrity actually adds to performance and quality-of-life for us as individuals, and for our families, groups, organizations, societies, and nations. Mastering these eleven factors will give you access to vast increases in integrity and performance.

\section{Not seeing that who you are as a person is your word}

That is, thinking that who you are as a person is anything other than your word. For example, thinking that who you are is your body, or what is going on with you internally (your mental/emotional state, your thoughts/thought processes and your bodily sensations), or anything else you identify with such as your title or position in life, or your possessions, etc... leaves you unable to see that when your word is less than whole and complete you are diminished as a person.

A person is constituted in language. As such, when a person's word is less than whole and complete they are diminished as a person.

\section{Living as if my Word is only What I Said (Word 1) and What I Assert Is True (Word 4)}

Even if we are clear that in the matter of integrity our word exists in six distinct ways, most of us actually function as if our word consists only of what I said or what I assert is true. This guarantees that we cannot be men or women of integrity. For us, Words 2, 3, 5, and 6 are invisible as our word:

- Word-2: What You Know to do or not to do

- Word-3: What Is Expected of you by those with whom you wish to have a workable relationship (unless you have explicitly declined those unexpressed requests)

- Word-5: What You Stand For

- Word-6: Moral, Ethical and Legal Standards of each society, group, and governmental entity of which I am a member

When we live (function in life) as though our word is limited to Word 1: What I Said and Word 4: What I say is so, we are virtually certain to be out of integrity with regard to our word as constituted in Words 2, 3, 5 and 6. In such cases, all the instances of our word (be it the word of an individual or organization) that are not spoken or otherwise communicated explicitly are simply invisible as our word to such individuals or organizations. In our lives, all the instances of our Words 2, 3, 5 and 6 simply do not show up (occur) for us as our having given our word.

\section{3. "Integrity is a virtue"}

For most people and organizations, integrity exists as a virtue rather than as a necessary condition for performance. When held as a virtue rather than as a factor of production, integrity is easily sacrificed when it appears that a person or organization must do so to succeed. For many people, virtue is valued only to the degree that it engenders the admiration of others, and as such it is easily sacrificed 
especially when it would not be noticed or can be rationalized. Sacrificing integrity as a virtue seems no different than sacrificing courteousness, or new sinks in the men's room.

\section{Self Deception about being out-of-integrity}

People are mostly unaware that they have not kept their word. All they see is the 'reason', rationalization or excuse for not keeping their word. In fact, people systematically deceive (lie to) themselves about who they have been and what they have done. As Chris Argyris concludes: "Put simply, people consistently act inconsistently, unaware of the contradiction between their espoused theory and their theory-in-use, between the way they think they are acting and the way they really act." 17

And if you think this is not you, you are fooling yourself about fooling yourself.

Because people cannot see their out-of-integrity behavior, it is impossible for them to see the cause of the unworkability in their lives and organizations - the direct result of their own attempts to violate the Law of Integrity.

\section{Integrity is keeping one's Word}

The belief that integrity is keeping one's word - period - leaves no way to maintain integrity when this is not possible, or when it is inappropriate, or when one simply chooses not to keep one's word. This leads to concealing not keeping one's word, which adds to the veil of invisibility about the impact of violations of the Law of Integrity.

\section{Fear of acknowledging that you are not going to keep your word}

When maintaining your integrity (i.e., acknowledging that you are not going to keep your word and cleaning up the mess that results) appears to you as a threat to be avoided (like it was when you were a child) rather than simply a challenge to be dealt with, you will find it difficult to maintain your integrity. When not keeping their word, most people choose the apparent short-term gain of hiding that they will not keep their word. Thus out of fear we are blinded to (and therefore mistakenly forfeit) the power and respect that accrues from acknowledging that one will not keep one's word or that one has not kept one's word.

\section{Integrity is not seen as a factor of production}

This leads people to make up false causes and unfounded rationalizations as the source(s) of failure, which in turn conceals the violations of the Law of Integrity as the source of the reduction of the opportunity for performance that results in 
failure.

\section{Not doing a cost/benefit analysis on giving one's word}

When giving their word, most people do not consider fully what it will take to keep that word. That is, people do not do a cost/benefit analysis on giving their word. In effect, when giving their word, most people are merely sincere (well-meaning) or placating someone, and don't even think about what it will take to keep their word. (How often do we all say something like "let's have lunch sometime" with out actually intending to set a date and place.) Simply put, this failure to do a cost/benefit analysis on giving one's word is irresponsible. Irresponsible giving of one's word is a major source of the mess left in the lives of people and organizations. People generally do not see the giving of their word as: "I am going to make this happen," but if you are not doing this you will be out-of-integrity. Generally people give their word intending to keep it. That is, they are merely sincere. If anything makes it difficult to deliver, then they provide reasons instead of results.

\section{Doing a cost/benefit analysis on honoring one's word}

People almost universally apply cost/benefit analysis to honoring their word. Treating integrity as a matter of cost/ benefit analysis guarantees you will not be a trustworthy person, or with a small exception, a person of integrity.

If I apply cost/benefit analysis to honoring my word, I am either out of integrity to start with because I have not stated the cost/benefit contingency that is in fact part of my word (I lied), or to have integrity when I give my word, I must say something like the following:

"I will honor my word when it comes time for me to honor my word if the costs of doing so are less than the benefits."

Such a statement, while leaving me with integrity will not engender trust. In fact that statement fundamentally says that my word is meaningless.

\section{Integrity is a Mountain with No Top}

People systematically believe that they are in integrity, or if by chance they are at the moment aware of being out of integrity, they believe that they will soon get back into integrity.

In fact integrity is a mountain with no top. We will never get to the place of $100 \%$ integrity. However, the combination of 1) generally not seeing our own out-ofintegrity behavior, 2) believing that we are persons of integrity, and 3) even when we get a glimpse of our own out-of-integrity behavior, assuaging ourselves with the notion that we will soon restore ourselves to being a person of integrity keeps us from seeing that in fact integrity is a mountain with no top. To be a person of integrity requires that we recognize this and "learn to enjoy climbing". 


\section{Not having your word in existence when it comes time to keep your Word}

People say "Talk is cheap" because most people do not honor their word when it comes time to keep their word. A major source of people not honoring their word, is that when it comes time for them to do so, their word does not exist for them in a way that gives them a reliable opportunity to honor their word.

Most people have never given any thought to keeping their word in existence so that when it comes time for them to keep their word there is a reliable opportunity for them to honor their word. This is a major source of out-of-integrity behavior for individuals, groups and organizations.

In order to honor your word, you will need an extraordinarily powerful answer to the question, "Where Is My Word When It Comes Time For Me To Keep My Word?" If you don't have a way for your word to be powerfully present for you in the moment or moments that it is time for you to take action to honor your word, then you can forget about being a person of integrity.

In Erhard, Jensen and Zaffron (2009, pp. 70-87) we distinguish each of these eleven factors in a way that gives one access to integrity, that is in a way that enables one to do the work required to pierce the Veil of Invisibility, and by doing so be left in the presence of the power that integrity confers on human beings and on human entities. In our experience individuals and organizations that master the eleven factors of the Veil of Invisibility provide themselves with access to a life of integrity with the power that integrity confers.

Thus in this work we go beyond "nudging" to actually give human beings and human entities access to eliminating or at least significantly reducing their out-of-integrity behavior. We must emphasize, however, that as we said above, integrity is a mountain with no top. Therefore those who set off on this task must learn to enjoy climbing because there is no end to the process. And as the climb continues life continues to get better.

In a very real sense being a person of integrity starts with me giving my word to myself that is, my word to myself that I am a person of integrity.

And, as a person of integrity, when I give my word to anything, it is as though I have said to myself:

"I am going to make this happen." And, being a person of integrity, it is a part of who I am that when I do not keep my word, without question I honor my word.

I never say to myself:

"I am going to try to make this happen" or "I hope this will happen" or even "I will do my best to make this happen".

\section{i. A Picture of What It Looks Like To Be In Integrity}

We do not have the space here, nor is it appropriate in this paper, to do what is necessary to provide our readers with a complete exposition required for full access to integrity. 
Nevertheless, we have provided some access so that you can, if you choose to, experiment with living with integrity in your personal and professional life. To aid in that experimenting, here is a picture that provides a sense of what it is like to live a life of integrity.

Since it is my word through which I define and express myself, both for myself and for others, it is not too much to say that who I am is my word, both who I am for myself and who I am for others. In any case, for a human being or other human entity integrity is a matter of one's word, nothing more and nothing less.

A Picture of Integrity. Illustrating with one's self what it means for a person, group, or entity to have integrity, picture what your life would be like, and what your performance would be, if it were true that:

- You have done what you said you would do, and you did it on time.

- You have done what you know to do, you did it the way it was meant to be done, and you did it on time.

- You have done what those with whom you desire a workable relationship expect you to do (even if they never asked you to do it and you never said you would do it), and you did it on time. Or, you have informed them in this or that case that you will not meet their expectations of you.

- Conversely, you have informed others of your expectations of them and have made explicit requests to those others.

- Whenever you have given your word as to the existence of some thing or some state of the world (assert something), you are willing to be held accountable that your evidence for what you are asserting would satisfy your listener(s) that your assertion is valid.

- And, whenever you realized that you were not going to do any of the foregoing, or not going to do it on time:

○ You have said so to everyone who might be impacted, and you did so just as soon as you realized that you wouldn't be doing it, or wouldn't be doing it on time, and

If you are going to do it in the future you have said by when you would do it, or if you are not going to do it at all, you have said so, and

You have dealt with the consequences of your not doing it on time, or not doing it at all, for all those who are impacted by your not doing it on time, or not doing it at all.

- Putting the foregoing all together: You have done what you said you would do, what you know to do, and what others expect you to do, or you have said you are not doing it, or not doing it on time, and you have cleaned up the mess you have caused by not doing it at all or not doing it on time. You have expressed your expectations of others through explicit requests. You are willing to be held 
accountable that your evidence for what you assert would satisfy the others. Finally, if you are not going to obey the rules of the game you are playing in, you have informed all others playing with you of that fact, and you willingly bear the consequences. In short, you have nothing hidden; you are truthful, forthright, straight, and honest.

- And, almost unimaginable: What would it be like if others operated in this way with you?

It follows then, that in order to be whole and complete as a person, my word to myself and to others must be whole and complete. What then is it like to be whole and complete as a person? When you keep or honor your word to yourself and others:

- You are at peace with yourself, and therefore you act from a place where you are at peace with others and the world, even those who disagree with you or might otherwise have threatened you.

- You live without fear for who you are as a person.

- You have no fear of losing the admiration of others.

- You do not have to be right; you act with humility.

- Everything or anything that someone else might say is ok for consideration. There is no need to defend or explain yourself, or rationalize yourself, you are able to learn.

- This state is often mistaken as mere self-confidence rather than the true courage that comes from being whole and complete, that is, being a man or woman of integrity.

\section{A BRIEF LOOK AT SOME AREAS IN FINANCE THEORY AND PRACTICE WHERE INTEGRITY IS LACKING}

We turn now to a discussion of the application of this purely positive theory of integrity to finance. We start with some common beliefs, recommended practices, and theory in finance that are inconsistent with being a person or a firm or a system of integrity. We list here some of these propositions and provide a detailed analysis below. Consider the following:

The long history in finance (not the law) of implicitly defining the fiduciary duty of managers to be to current shareholders only, and therefore ignoring future shareholders and current and future bondholders and other claimants on the firm.

- As an example of this we point to the common recommendation for managers with an overvalued stock to issue new stock at the current high price (or make acquisitions using overvalued shares as payment) to benefit current shareholders at the expense of future shareholders, and (implicitly) to hide what they are doing.

- Common budgeting practices and target-based compensation plans that pay people according to how close they meet their targets. 
- "Managing relations" with capital markets in a way that views financial reporting choices as strategic and must be made to both manage what the "street" expects and to give the street what it expects (basically manipulation of the "street").

Each of these recommended practices is out of integrity and leaves the entity being out of integrity - that is, not whole and complete as to its word. These practices thus create unworkability and therefore destroy value.

Consider, for example, the common recommendation (noted above) for firms whose equity or debt is overvalued to sell stock or bonds at those overvalued prices. That out-ofintegrity recommendation (not whole and complete as to its word) is bound to lead to value destruction. The same is true of advice to use that over-valued equity to acquire a lessovervalued firm for stock (implicitly hiding what is being done). In both of these cases the management of the overvalued firm is violating the firm's implicit word to its financial claimants that it will not intentionally take actions that harm them. This is an example of the situation where an individual or an organization is out of integrity if that individual or organization does not either 1) comply with the expectations of their financial claimants that are unexpressed requests (expectations based on the firm's implicit word to its financial claimants), or 2) explicitly and clearly decline those expectations. (See the definition of Word-3 and Word-4 discussed above in Section 2 and more completely in the online Appendix 2: One's Word Defined) available at: http://www.nber.org/data-appendix/w19986/

When new shareholders discover that they were taken, workability will decrease and value will be destroyed.

Note, however, that the law does provide some obligation of the firm to future bondholders and shareholders through disclosure rules and regulations. But consider the attitudes of sellers of new issues and the investment bankers who counsel them. Few CEOs and few investment bankers who advise them seem to take seriously any obligation of the firm to future bondholders and shareholders when pricing a new issue.

When a CEO takes a firm public by selling shares or bonds to the public, he or she is creating a fiduciary relationship between himself and his company and the holders of those securities. The word he or she gives implicitly and explicitly to those purchasers regarding the value of those securities is an important part of that relationship. That word must be given with the same standards as that of the fiduciary relationship the sale creates. If the CEO or investment bankers speaking for the firm misrepresent, withhold information, or otherwise mislead those purchasing the securities, the firm is out of integrity and the fiduciary relationship the transaction creates is sullied. Therefore the ongoing workability of that relationship is damaged.

\section{THE PUZZLING STATE OF LOW-INTEGRITY BEHAVIORAL STANDARDS IN CORPORATIONS AND CAPITAL MARKETS}

Here is a list (albeit incomplete) of common actions and activities that result in the word of executives and firms being less than whole, complete, unbroken, unimpaired, sound, in perfect condition. In short, these common actions and activities leave those executives and those firms "out-of-integrity". Out-of-integrity behavior results in reduced workability and a reduced opportunity for performance, and therefore destroys value. The remainder of this paper is focused on surveying from the integrity perspective examples of these practices so that we begin 
to focus on the value that can be created by putting the system back in integrity and correcting the apparent non-value maximizing equilibrium that exists in financial markets.

\section{a. Financial Reporting}

Managers regularly choose to treat the firm's relations with the capital markets as a game where financial reporting is not driven by creating long-term value but is little more than a strategy for managing and meeting analyst expectations. Managing earnings, income smoothing, and manipulating financial analysts does not leave the word of executives or the word of the firm whole and complete. These practices invariably leave executives and firms out-of-integrity with respect to Word-4 ("one's word as to the existence of some thing or some state of the world includes being accountable that the other would find valid for themselves the evidence that one has for asserting something to be the case" - see pages 17 , and $56 .{ }^{18}$

Until recently it was generally considered part of every top manager's job to "manage earnings" - that is, to report earnings other than as they actually are (and while somewhat less so now, this still tends to be true. When managers give their word to something other than what is actually so (in this case, their word as to the accuracy of the firm's reported financial statements), this leaves them less than whole and complete, and diminishes the opportunity for performance. That is, such fudging undermines the opportunity for maximizing firm value. For too long we in finance have implicitly condoned or even collaborated in these activities. Specifically we are referring to "managing earnings", "income smoothing", etc. These issues are not merely one of deciding on a strategy - they directly involve integrity and the generally unappreciated, negative long-run value effects of such out-of-integrity behavior.

Making organizational operating decisions other than those that maximize long-term firm value so as to manage reported earnings is a violation of Word-4. If the markets had the evidence that we managers had when making such earnings management decisions the markets would come to a different conclusion about the meaning of those managed earnings. That, incidentally, is the reason the various manipulations of accounting and real operating decisions are not fully disclosed to the markets. In everyday language violating Word-4 is "lying". When we use terms other than lying to describe a violation of Word-4 we inadvertently encourage the sacrifice of integrity. We have observed perfectly honest upstanding people in their roles as board members condone manipulation of financial reports because it does not occur to them as lying-it occurs to them as just part of what it means to manage. Such language effectively disables even the normal social sanctions that would limit such behavior in boardrooms and among managers as they openly discuss how to "manage earnings".

As we said above, language affects the way in which what is being dealt with occurs to people. And the way what is being dealt with occurs to people affects their behavior. ${ }^{19}$ When

18 See Fuller, Joseph and Jensen, Michael C., Just Say No to Wall Street: Putting a Stop to the Earnings Game (April 5, 2010). Journal of Applied Corporate Finance, Vol. 22, No. 1, Winter 2010; Harvard Business School NOM Unit Working Paper No. 10-090. Available at SSRN: http://ssrn.com/abstract=1583563

19 See Erhard, Werner, Jensen, Michael C. and Group, Barbados, A New Paradigm of Individual, Group, and Organizational Performance (November 17, 2010). Harvard Business School NOM Unit Working Paper No. 11-006; Barbados Group Working Paper No. 09-02. Available at SSRN: http://ssrn.com/abstract=1437027 
executives and firms give their word to something other than what is actually so (that is, manage earnings), it shifts the way in which the firm occurs to its executives. Their focus shifts away from maximizing value to how to win the short-term gains from manipulating analysts and the expectations of the market.

\section{b. Investment Banks Defrauding Clients}

On the part of banks and investment banks misleading clients with misleading investment recommendations that clients have been led to believe are intended to serve the client is not whole and complete with regard to their word. Goldman Sachs, for example, was accused of intentionally misleading its clients in the Abacus mortgage backed securities which were intentionally structured to fail (for which Goldman paid a \$550 million settlement, at the time the largest ever in the history of the SEC). ${ }^{20}{ }^{21}$ Consistent with the dramatic decline in organizational integrity at Goldman Sachs in recent years, Greg Smith resigned as executive director and head of Goldman's United States equity derivatives business in Europe, the Middle East and Africa on March 14, 2012 with his New York Times Op Ed article entitled "Why I am Leaving Goldman Sachs". ${ }^{22}$ Quoting Smith:

After almost 12 years [at Goldman Sachs] ... I believe I have worked here long enough to understand the trajectory of its culture, its people and its identity. And I can honestly say that the environment now is as toxic and destructive as I have ever seen it. To put the problem in the simplest terms, the interests of the client continue to be sidelined in the way the firm operates and thinks about making money. . . . culture was always a vital part of Goldman Sachs's success. It revolved around teamwork, integrity, a spirit of humility, and always doing right by our clients. The culture was the secret sauce that made this place great and allowed us to earn our clients' trust for 143 years. It wasn't just about making money; this alone will not sustain a firm for so long. . . .

... Today, if you make enough money for the firm (and are not currently an ax murderer) you will be promoted into a position of influence.

What are three quick ways to become a leader [at Goldman]? a) Execute on the firm's "axes," which is Goldman-speak for persuading your clients to invest in the stocks or other products that we are trying to get rid of because they are not seen as having a lot of potential profit. b) "Hunt Elephants." In English: get your clients - some of whom are sophisticated, and some of whom aren't - to trade whatever will bring the biggest profit to Goldman. Call me old-fashioned, but I don't like selling my clients a product that is wrong for them....

... I attend derivatives sales meetings where not one single minute is spent asking questions about how we can help clients. It's purely about how we can make the most possible money off of them.

....It makes me ill how callously people talk about ripping their clients off. Over the last 12 months I have seen five different managing directors refer to their own clients as "muppets," sometimes over

20 See Dealbook (2010), and the Appendix to Jensen, Michael C. and Erhard, Werner, A 'ValueFree' Approach to Values (PDF File of Powerpoint Slides) (April 11, 2011). Harvard Business School NOM Unit Working Paper No. 11-010; Barbados Group Working Paper No. 10-06; Simon School Working Paper No. FR10-26. Available at SSRN: http://ssrn.com/abstract=1640302

21 Securities and Exchange Commission, "Goldman Sachs to Pay Record \$550 Million to Settle SEC Charges Related to Subprime Mortgage CDO”, July 15, 2010. http://www.sec.gov/news/press/2010/2010-123.htm

22 "Why I am Leaving Goldman Sachs", New York Times, March 14, 2012, http://www.nytimes.com/2012/03/14/opinion/why-i-am-leaving-goldman-sachs.html?_r=1\&hp 
internal e-mail. ... No humility? I mean, come on. Integrity? It is eroding. I don't know of any illegal behavior, but will people push the envelope and pitch lucrative and complicated products to clients even if they are not the simplest investments or the ones most directly aligned with the client's goals? Absolutely. Every day, in fact.

It astounds me how little senior management gets a basic truth: If clients don't trust you they will eventually stop doing business with you. It doesn't matter how smart you are.

... People who care only about making money will not sustain this firm — or the trust of its clients — for very much longer.

Based on the evidence summarized by Smith, the conversation within Goldman Sachs about its relation to clients (or stated as a matter of integrity, "the firm's word to itself about its relation to clients") is obviously inimical to the interests of its clients. What is clearly hidden from Goldman Sachs' management is that such behavior, because it is out-of-integrity, is also inimical to Goldman's own interests. You will see the out-of-integrity behavior in the conflict between the firm's word to itself about its relation to clients, and its word to its clients. And as Smith says about the resulting damage to the firm from such behavior, "If clients don't trust you they will eventually stop doing business with you".

On its website, Goldman Sachs represents itself and gives its word to the world (including its clients) in the statement of its "Business Principles and Standards: Goldman Sachs Business Principles".23 The first and last of Goldman's 14 business principles state:

Our clients' interests always come first. Our experience shows that if we serve our clients well, our own success will follow.

Integrity and honesty are at the heart of our business.

This specific out-of-integrity behavior in the financial world is not limited to Goldman Sachs.

Given what Smith reveals about the conversation within Goldman Sachs about the firm's relation to clients (the firm's word to itself), Goldman Sachs' word to its clients is clearly not whole, and is incomplete and broken - the very definition of out-of-integrity. The obvious cost to Goldman Sachs and other firms of not seeing the impact of out-of-integrity behavior is the cost of lawsuits, penalties, and settlements. But the impact on clients' behavior, and the extent of the impact on the reputation and morale of the firm is much less obvious, and sometimes dismissed as just the cost of doing business.

Smith is dumbfounded at the firm's not seeing the self-inflicted damage from its out-ofintegrity behavior, “... how little senior management gets a basic truth: If clients don't trust you they will eventually stop doing business with you." [emphasis added] The source of what dumbfounds Smith (what hides the damage from out-of-integrity behavior) is discussed above in Section 2.i on page 17. The Veil of Invisibility. In that Section we argue that mastering the eight factors that constitute the Veil of Invisibility creates actionable access to eliminating the damage

23 See http://www.goldmansachs.com/who-we-are/business-standards/business-principles/index.html 
done by out-of-integrity behavior, or at least unconceals the behaviors that are generating the damage. ${ }^{24}$

Consistent with Smith's judgments regarding Goldman Sachs' out-of-integrity behavior, Bodnaruk, et al (2007), in their study of "The Dark Role of Investment Banks in the Market for Corporate Control" find the behavior goes far beyond just Goldman Sachs. As they conclude (p. 1):

We argue that advisors are privy to information about the deal that they directly exploit in the market by investing in the target. We show that the banks' advisors to the bidders tend to have positions in the target before the deal. The existence of a direct stake of the advisor to the bidder increases the probability of the bid and the target premium. Advisory banks profit from such a position. A trading strategy that conditions on the stake of the advisors delivers a net-of-risk performance of $4.08 \%$ per month. This cannot be replicated with available information. We also show that advisors not only take positions in the deals they advise on, but also directly affect the outcome of the deal and its probability of success. This has negative implications for the viability of the new entity.

\section{c. Money Managers Defrauding Clients}

Money managers have allowed certain favored investors to engage in market-timing operations (for example, after-hours trading at stale prices) that allowed these favored investors to sell or purchase shares at prices above or below the actual value of those shares. Such practices allow those favored investors to transfer wealth from non-favored fund investors to themselves. Well-known fund organizations that were accused of allowing such behavior (and fired employees as a result of the investigations and/or paid penalties to settle the charges) include Putnam Investments, Strong Capital Management, Morgan Stanley, Janus Capital Group, Bear Stearns, Bank of America and Invesco. ${ }^{25}$ In some cases the managers of the funds (for example, Strong Capital Management) engaged in such trading themselves in personal violation of their fiduciary duties to fund investors. ${ }^{26}$

24 Interestingly, Smith's book, Why I Left Goldman Sachs: A Wall Street Story, has been criticized by figures in the financial press and members of the financial community. Smith's book clearly indicates a serious lack of integrity at Goldman, and it is consistent with the out-of-integrity actions that Goldman has taken in such deals as the Abacus 2007-AC1 mortgage backed securities issue. We conjecture that many in the Wall Street community considered the book's accusations unimportant because they expected and did not find documentation of actual illegal behavior in the book. There is considerable discussion of outof-integrity behavior and the damage it is likely to cause, although Smith does not use that specific language. That itself says something about the culture of the Wall Street finance community.

25 See Burton (2003), Smith and Lauricella, "Moving the Market: Bear Stearns to Pay \$250 Million Fine; Net Rises 36\%," Wall Street Journal (2006) and Anand, "Harmed Investor? Just Wait - Brokerage Firms Pay $\$ 255$ Million, but Getting It Takes Time," Wall Street Journal (2006).

26 See Lauricella and Oster, "Strong Funds And Regulators To Settle Case - Agreement Would Clear the Way For Possible Sale to Wells Fargo; Considerable Challenges Ahead," Wall Street Journal (2004), Lauricella and Oster, "Second Strong Executive Snagged in Probe - Anthony D'Amato of CEO's Office Was Involved in a Deal to Allow Canary to Rapidly Trade Shares," Wall Street Journal (2003), and Lauricella, "Strong Steps Down From Board But Stays On as Head of Firm," Wall Street Journal (2003). 


\section{CORPORATE GOVERNANCE: PUTTING INTEGRITY INTO THE ORGANIZATION AS A SYSTEM AND AS A HUMAN ENTITY}

\section{a. Put Integrity Into Boards of Directors}

Boards of directors are ultimately accountable for the performance of the organization as a whole. This accountability for performance includes the performance of 1) the organization as a system, and 2) the organization as a human entity.

- We specify the organization as a system as follows: the design of the system, the implementation of the design, and the use of the system.

- We specify the organization as a human entity as follows: the word of the entity itself (includes those individuals who are taken to speak for the organization), and the word of the individuals who make up the entity.

- When an organization is out of integrity, be it out of integrity as a system or out of integrity as a human entity, (or both) the organization is in some way less than whole, complete, unbroken, unimpaired, sound, in perfect condition.

- When an organization as a system or as a human entity is less than whole, complete, unbroken, unimpaired, sound, in perfect condition, the workability of the organization as a system or as a human entity (or both) is diminished.

- When the workability of an organization as a system or as a human entity is diminished, the organization's opportunity for performance is diminished.

Given that boards of directors are ultimately accountable for organizational performance, and given that out-of-integrity behavior of the organization as a system or as a human entity diminishes the organization's opportunity for performance, this necessarily leaves boards of directors accountable for the integrity of the organization - the organization both as a system and as a human entity.

An organization's executive compensation plan is an example of the organization as a system. The board of directors is ultimately accountable for the workability and performance of that system. The board of directors is therefore necessarily accountable for the integrity of 1) the design of the system (the organization's executive compensation plan), 2) the implementation of that design, and 3) the use of the implemented system. An example of an out-of-integrity design of an organization's executive compensation plan is the budget or target-based executive compensation plan that most companies use. ${ }^{27}$

In addition, what gets said and what is unsaid in an organization's boardroom is an example of the organization as a human entity. Integrity for a human entity is a matter of that entity's word, nothing more and nothing less. When what is said in the organization's boardroom is less than whole, complete, unbroken, unimpaired, sound, in perfect condition, such out-of-

27 See Murphy, Kevin J. and Jensen, Michael C., CEO Bonus Plans: And How to Fix Them (November 19, 2011). Harvard Business School NOM Unit Working Paper 12-022; Marshall School of Business Working Paper No. FBE 02-11. Available at SSRN: http://ssrn.com/abstract=1935654 
integrity behavior diminishes the workability of the board. When workability is diminished, the opportunity for performance is diminished.

An example of out-of-integrity behavior in boards of directors (or for that matter, executive teams) is the existence of "undiscussables" in the board room - that is, what the firm may be getting by with, but is so questionable that if it is put up on the table it probably has to cease. Anything that is undiscussable leaves the board as a human entity less than whole, complete, unbroken, unimpaired, sound, in perfect condition. As a result, workability and value are sacrificed. No human entity in which there are issues that are undiscussable can be whole and complete.

If you doubt that there are undiscussables in the background of most board meetings and indeed most executive committees just try raising the issue of one or more undiscussables. You will quickly discover that it is undiscussable that there are undiscussables. These undiscussables are always trouble waiting to happen and there is no way to head off the trouble as long as the issues are undiscussable.

\section{b. Indicators of the Lack of Integrity In the Governance and Management of Financial Firms and their Advisors}

These indicators of a lack of integrity includes those professional firms who serve both the supply and demand side of financial services. Specifically this includes, law firms, banks, investment banks, brokerage firms, accounting firms, and consulting firms (especially compensation consultants) as well as other financial service firms including mutual funds, hedge funds, and private equity funds.

For managers and directors of financial firms and their advisors Forstmoser (2006), in his speech "Integrity in Finance" given to the Swiss Banking Institute, offers some all-too-common explicit indicators of the existence of out-of-integrity behavior in their organizations:

"Everyone else is doing it."

"We've always done it."

"This is the way this business works."

"If we don't do it, somebody else will."

"Nobody's hurt by it."

"It doesn't matter how it gets done, as long as it gets done."

"It works, so let's not ask too many questions."

"No one's going to notice and besides we will fix it before they do."

"It's legal, but ...."

"It's too expensive."

"It has to be done to save the organization, and by the way a lot of jobs."

Because the widespread lack of integrity in organizations reduces long-term value, it raises the question: How can it persist if it destroys long-run value? We address this issue in the next section. 


\section{THE GENERAL LACK OF INTEGRITY IN RELATIONS WITH CAPITAL MARKETS}

There are many reasons for the lack of integrity in the relations between firms and capital markets, but a major contributor to this situation is that markets reward and punish managers in ways very similar to those budget-based compensation systems that "pay people to lie". That is, systems that pay people to "under promise and over deliver". Indeed, many readers have undoubtedly heard managers and executives explicitly announce "under promise and over deliver" as a management philosophy. It is certainly out of integrity.

Stripping away the politeness, a management or behavioral philosophy of "under promise and over deliver" actually means in many situations: "lie and lie". I lie to you about what I can deliver, and I lie to you about what is actually delivered - another example of violations of Word-4. Put this way it is obvious what happens to integrity, trust and reliability in cultures where such behavior becomes generally accepted. We now turn to an analysis of one of the market forces that encourage managers to engage in gaming behavior such as under promise and over deliver.

Figure 1 below from Skinner and Sloan (2002, p. 209) illustrates vividly how markets reward and punish managers for meeting or beating the analysts' consensus quarterly earnings forecast over the period 1984-1996. The graph plots quarterly abnormal returns for growth firms and value firms as a function of earnings surprise at the end of the quarter. Forecast error is measured as the earnings surprise relative to the quarter-end stock price. Growth firms are those with high market value to book value ratios, and Value firms are those with low market value to book value ratios. Data is from $\mathrm{I} / \mathrm{B} / \mathrm{E} / \mathrm{S}$ database for the final month of the fiscal quarter for which earnings is being forecast. Sample size is 103,274 firm-quarter observations in the period 1984-1996.

A $1 \%$ positive earnings surprise results on average in a $10 \%$ abnormal stock return for growth firms and approximately a $-15 \%$ abnormal stock return for missing the quarterly earnings forecast by $1 \%$. For value firms (non-growth firms) the comparable abnormal returns are $6 \%$ and $-3 \%$ respectively. Managers of a firm facing these sorts of rewards and punishments from the capital markets have incentives to take long-run value-destroying actions to satisfy the market's short-run expectations. 


\section{Figure 1: How Markets Reward and Punish Managers for Meeting or Beating Consensus Forecasts}

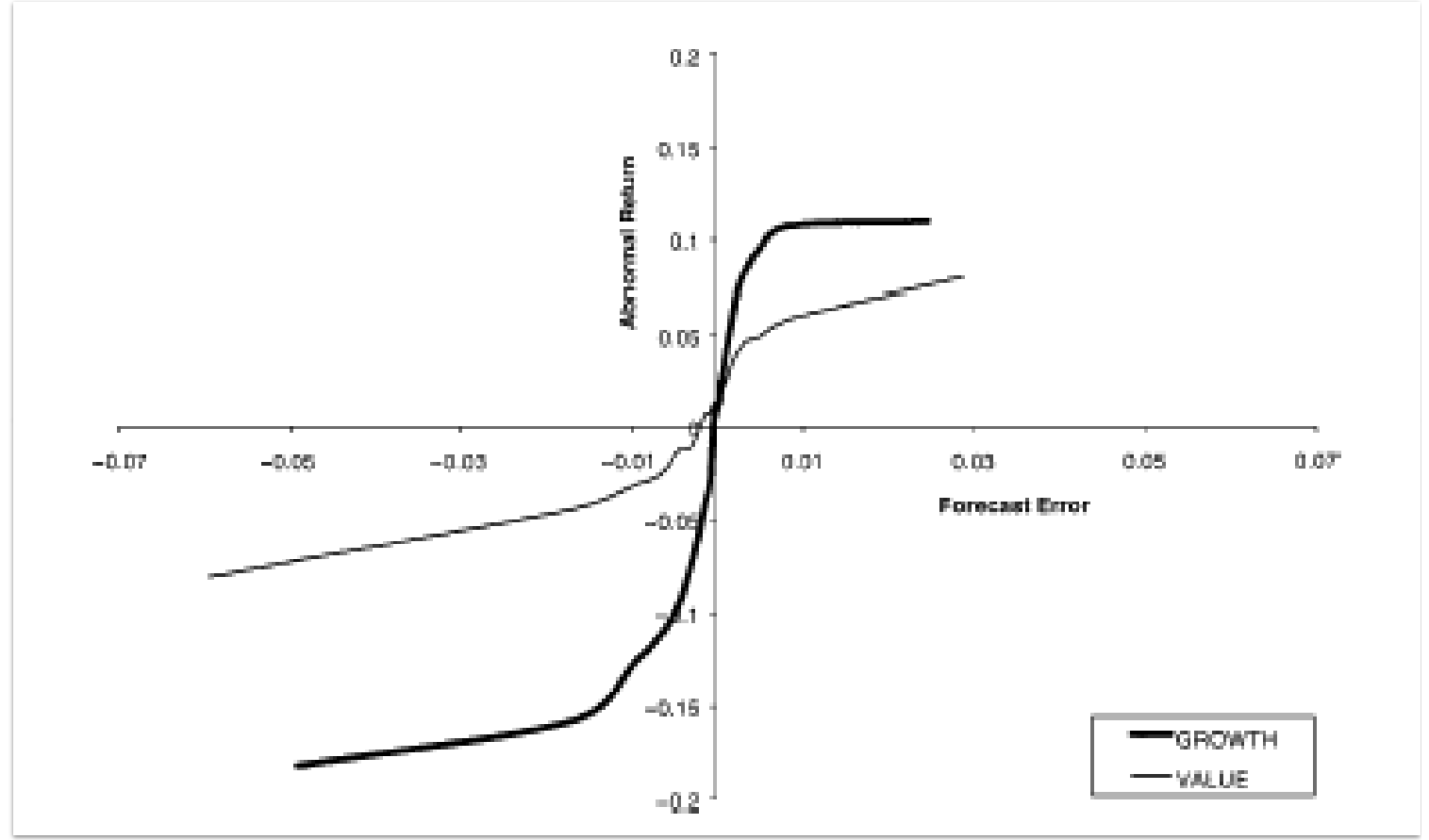

Source: Skinner \& Sloan (2002, p. 209)

Interestingly, the relation between a firm's top-management team and the capital markets has resulted in an equilibrium that replicates many counterproductive aspects of corporate internal budget or target-based bonus systems. Thus, the capital markets provide further shortrun incentives for manager's to take out-of-integrity actions to meet market expectations. ${ }^{28}$

For corporate executives holding large quantities of restricted stock and stock options, Figure 1 portrays the pay-performance relation that defines how meeting, beating or missing analyst forecasts affects the value of their equity-based holdings. Figure 1 has the same general shape as a smoothed version of the typical non-linear managerial bonus pay-performance relation depicted in Fig. 2 below and discussed in Murphy and Jensen (2011), and produces the same counterproductive incentives. Therefore we discuss in some detail the incentives managers face under the bonus plans represented in Fig. $2 .^{29}$

28 See, for example, Murphy and Jensen (2011) "CEO Bonus Plans and How to Fix Them," and Jensen (2001), "Corporate Budgeting Is Broken: Let's Fix It", and Jensen, Michael C., Paying People to Lie: The Truth About the Budgeting Process (Revised September, 2001).

29 For an excellent article on the history and structure of CEO pay see: Murphy (forthcoming 2013) "Executive Compensation: Where We Are, and How We Got There". 


\section{Figure 2: How Typical Management Bonus Plans Reward and Punish Managers for Meeting or Beating Internal Performance Targets ${ }^{30}$}

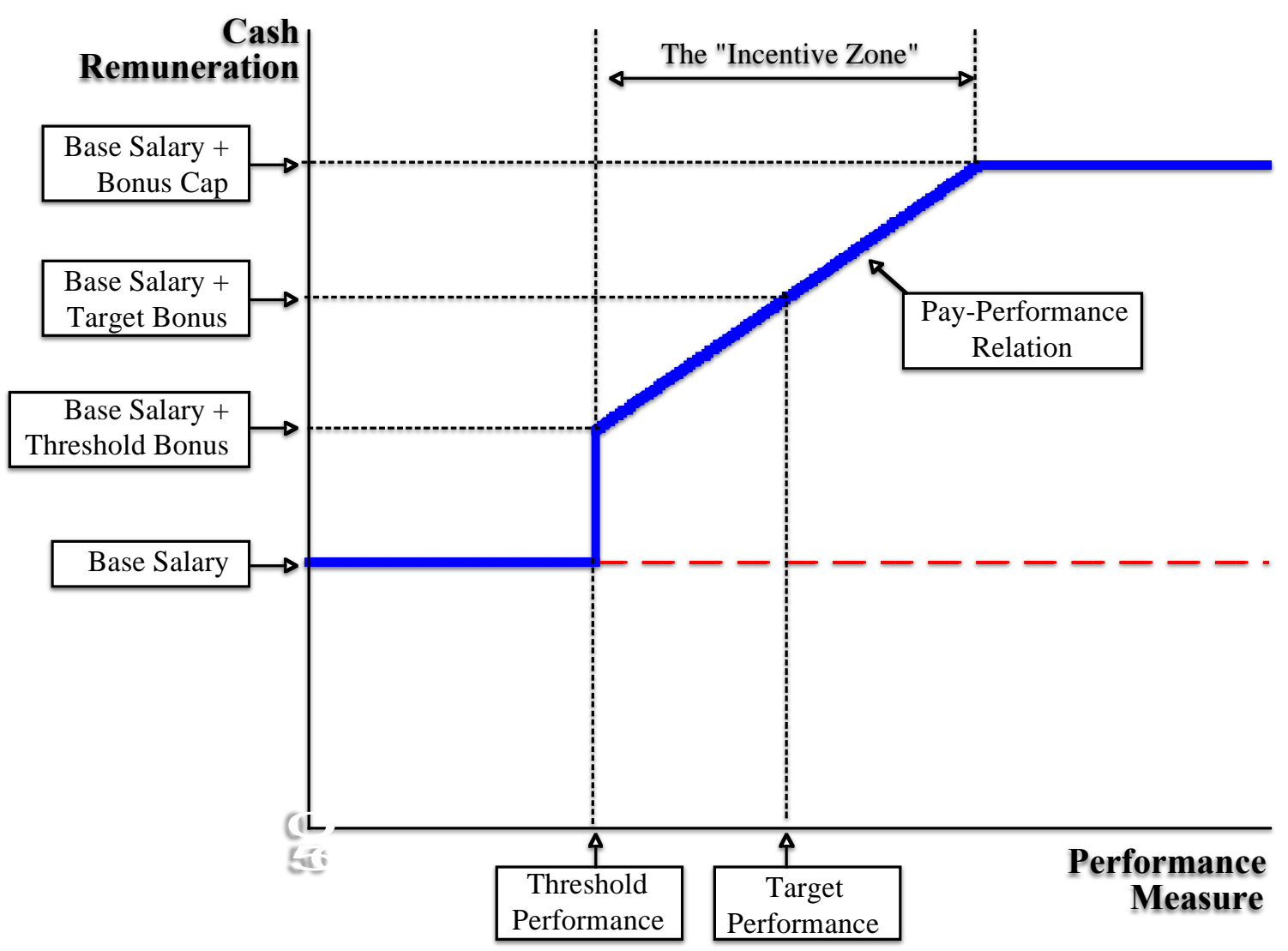

Figure 2 illustrates the common management compensation practice in which a manager's salary plus bonus is constant until a minimum "threshold performance" is reached commonly $80 \%$ of the "target" or budgeted performance level. At $80 \%$ of the target performance the manager receives a bonus for making the threshold performance target. This bonus is often substantial, and as performance increases above this hurdle the bonus increases until it is capped at some maximum (120\% of the target performance is common). Performance above this upper limit generates no additional bonus.

Consider managers' incentives when they are struggling to reach the minimum hurdle. In this situation as long as they believe they can make the threshold performance, managers will engage in actions to increase their performance, and this can be done by legitimate or illegitimate means. When the measure is profits, or some variation of profits, managers have incentives to

30 Source: Jensen (2001) "Paying People to Lie: The Truth About the Budgeting Process", and Murphy and Jensen (2011), "CEO Bonus Plans and How to Fix Them". 
increase this year's profits at the expense of future year's profits by moving expenses from this year to the future (by delaying purchases, for example) or by moving revenues from future years into this year by booking orders early, by announcing future price increases, by giving special discounts this year, or by guaranteeing to repurchase goods in the future, and so on). When these actions simply move profits from one year to another the adverse impact on firm value is probably small. But, it can pay managers today to engage in actions that reduce the total value of firm cash flows by moving profits to the current period even when future profits are dramatically reduced.

When managers conclude that they cannot make the minimum threshold hurdle, their incentives shift dramatically because if the manager is going to miss the bonus this year, there is no further reduction in compensation from performance that is even farther away from the lower threshold amount (subject always to the condition that the manager is not fired). In this situation managers have incentives to do the opposite of what we just described, that is they now have incentives to move profits (if that is the performance measure) from the present to the future. They can do this by moving expenses from the future to the present period (by prepaying expenses, taking write-offs for restructuring, etc.), and by moving revenues from the present to the future. ${ }^{31}$ This is the "big bath theory", and the phenomenon is regularly observed when firms faced with missing analyst expectations take a "big bath" to improve their ability to meet analyst expectations in the future.

Finally, manager's who are within reach of the bonus cap have incentives to not exceed the cap because they get no rewards beyond that point (and these perverse incentives are even stronger if this year's performance is used in setting next year's targets). In this situation managers have incentives to move expenses from the future to the present and revenues from the present to the future to avoid exceeding the bonus cap this year and to increase bonuses in future years. And again, managers have incentives to do this even if it imposes real costs on the company.

Suffice it to say that all of the behavior described above is a violation of Word-4 and is therefore out of integrity and leads to unworkability and value destruction. And note that all this destructive behavior by the human beings in the organization is motivated by the fact that this common bonus plan is out-of-integrity in its design as a system. Eliminating this counterproductive behavior must start by eliminating the lack of integrity in the design of the compensation system. Asking the human beings operating in this badly designed system to change their behavior will fail unless and until the compensation system itself is redesigned to put it into integrity.

Popular recommendations to solve these incentive problems in the banking and financial industry as a whole tend to focus on eliminating bonuses, often motivated by the perception that the way the bonus plan works leaves top people paid "too much" rather than the bonus plan rewards people in the wrong way and for the wrong things. This approach addresses nothing about the design of these plans and ignores the potentially huge damaging effects associated with a mass exodus of highly qualified people from the banking and financial industry.

31 Healy (1985) provides an excellent study of the effects of bonus schemes on managers' choice of accounting policies. 


\section{FURTHER EVIDENCE ON MANAGEMENT MANIPULATION OF EARNINGS}

\section{a. Evidence from a survey of 401 CFO's reveals a fundamental lack of integrity}

Graham, Harvey \& Rajgopal's survey ${ }^{32}$ of 401 CFOs find that $78 \%$ of surveyed executives are willing to knowingly sacrifice value to smooth earnings. While it seems that recent scandals have made CFOs less willing to use accounting manipulations to manage earnings, this survey indicates that to meet short-run earnings targets CFOs are willing to change the real operating decisions of the firm and thereby destroy long run value. When smoothing earnings, it is true that a CFO would maintain his/her integrity (their word, and their firm's word, being whole, complete, etc.) by making something like the following public announcement each time they make such value-destroying decisions, "Given how I am paid, I am rejecting or delaying a firm-value-increasing project in order to meet analysts' consensus earnings forecast so as to increase my own pay." We would guess that relatively few CEOs and CFOs would actually make such announcements to their board of directors, the analysts, and the public.

\section{b. Aggregate evidence on the manipulation of corporate earnings.}

Figure 3 displays the aggregate evidence from the DeGorge, Patel and Zeckhauser (1999, p. 20) study of the errors (measured in cents per share of corporate earnings) between actual earnings and analyst consensus earnings forecast for over 100,000 quarterly observations on over 5,000 firms in the 1974-1996 period. The distribution is not symmetrically distributed around zero. In fact, there are far too many observations at exactly 0 as indicated by the center tall bar.

Indeed, the black areas below the $\mathrm{X}$-axis denote the deficiency in frequency of observations in the intervals of the distribution that would be expected if the true underlying distribution were symmetrical around zero. There are far too few observations in the intervals between -4 cents per share and -1 cent per share (where firms have missed analysts' consensus earnings forecast by a small amount) and far too few observations in the intervals greater than +4 cents per share (where firms significantly exceeded the analyst forecasts).

These results are consistent with the hypothesis that management is manipulating earnings to show far too many instances of quarterly earnings reports that exactly meet or just beat analyst expected earnings and far too few instances of quarterly earnings reports in the interval of -1 and -4 cents per share below analysts expected earnings. This is accomplished by reporting lower than actual earnings when earnings would be substantially above analyst expectations and "storing" the hidden earnings so that the firm could report just meeting or beating analyst expectations when the firm's earnings actually would have come in below those expectations.

32 Graham, John R., Harvey, Campbell R. and Rajgopal, Shivaram, The Economic Implications of Corporate Financial Reporting (January 11, 2005). Available at SSRN: http://ssrn.com/abstract=491627 


\section{Figure 3: Aggregate Evidence on the Manipulation of Earnings}

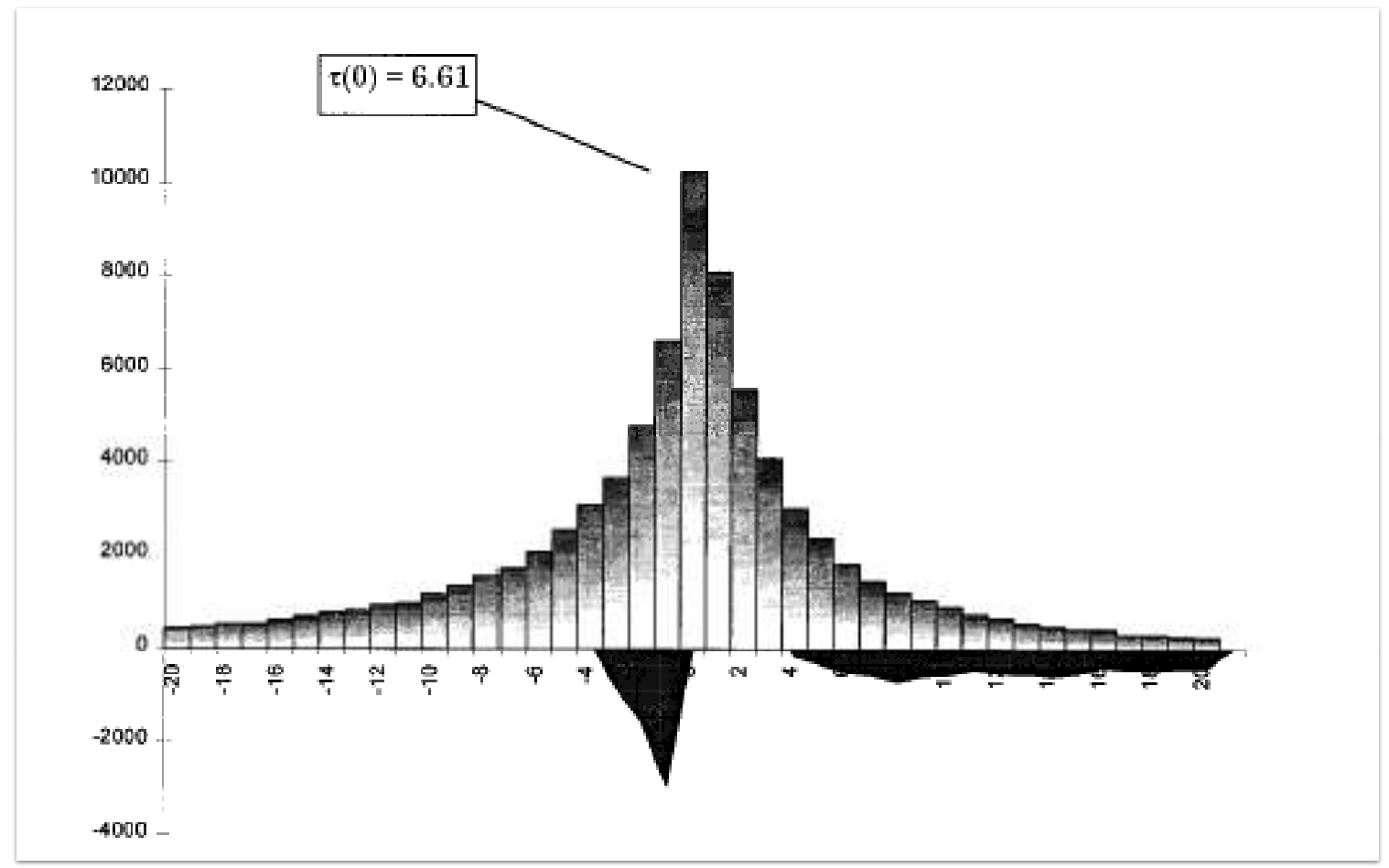

Source: DeGorge, Patel and Zeckhauser (1999)

Figure 3 displays the frequency distribution of the the aggregate evidence from the DeGorge, Patel and Zeckhauser (1999, p. 20) study of the errors between actual earnings and analyst consensus earnings forecast (measured in cents per share of corporate earnings) for over 100,000 quarterly observations on over 5,000 firms in the 1974-1996 period. The distribution is not symmetrically distributed around zero. In fact, there are far too many observations at exactly 0 as indicated by the center tall bar. The black areas below the $\mathrm{X}$ axis denote the deficiency in frequency of observations in the intervals of the distribution that would be expected if the true underlying distribution were symmetrical around zero. There are far too few observations in the intervals between -4 cents per share and -1 cent per share (where firms have missed analysts' consensus earnings forecast by a small amount) and far too few observations in the intervals greater than +4 cents per share (where firms significantly exceeded the analyst forecasts).

\section{c. And the manipulation of earnings extends to the reporting of hedge fund returns}

It appears that hedge funds regularly report smooth month-to-month returns. This apparently results from the fact that being able to say: "We have only had X months of negative returns" (X being a very small number) has a big impact on attracting investors to the fund. This means that reporting a return of $+.01 \%$ rather than $-.01 \%$ in any month leads to a large advantage in recruiting and retaining investors. And consistent with this, the evidence indicates that the 
distribution of returns for "hard to value" hedge funds shows way too many monthly returns just above zero and way too few just below zero. ${ }^{33}$ This is consistent with the hypothesis that hedge funds systematically underprice the value of the fund during the year so that they can smooth out the returns from month to month and avoid reporting negative returns in any month.

Consistent with this hypothesis that hedge funds manipulate the month-to-month value of their funds to serve their own interest, the contractual features of hedge funds provide them strong incentives to inflate returns in December of each year. And the evidence indicates they do so. Hedge funds earn incentive fees if they beat their contractual benchmarks and better performance increases investor contributions to the fund. Agarwal, Daniel and Naik (2010). provide strong evidence documenting this phenomenon. They find that the average December return is more than twice as high as the average returns for the entire 11 months January through November (Table II). In the authors' words (p. 37):

\footnotetext{
"In this paper, we provide strong evidence of hedge funds inflating their returns in an opportunistic fashion to increase their compensation. Specifically, we find funds that stand to gain the most from good performance, the funds that stand to lose the most from poor performance, and the funds that have greater opportunities to engage in return inflation exhibit the greatest spike in December returns. ... We also provide evidence on two potential mechanisms employed by hedge funds to manage returns. [The] first method involves funds underreporting their returns in the early part of the year in order to create reserves for possible poor performance later in the year (saving for the rainy day). In case some of these reserves are left unutilized, they get added to the December returns resulting in the spike. [The] second mechanism involves funds borrowing from their January returns of the subsequent year to improve their December returns. This can be achieved by funds pushing up the security prices at December-end by last-minute buying, which is followed by price reversals in January."
}

\section{d. And This Violation of Word-4 (the other would find the evidence for my assertion also valid for themselves) Extends to the Reporting of Analyst Recommendations}

Ljungqvist, Malloy, and Marston (2007) in their paper "Rewriting History" study the major historical database of financial analyst stock recommendations and find substantial evidence that the historical record, as reported in the widely used I/B/E/S database produced by Thomson Financial, does not represent the recommendations that were actually made by many of the analysts. They conclude: ${ }^{34}$

Comparing two snapshots of the entire historical I/B/E/S database of research analyst stock recommendations, taken in 2002 and 2004 but each covering the same time period 1993-2002, we identify tens of thousands of changes which collectively call into question the principle of replicability of empirical research. The changes are of four types: 1) The non-random removal of 19,904 analyst names from historic recommendations ("anonymizations"); 2) the addition of 19,204 new records that were not previously part of the database; 3 ) the removal of 4,923 records that had

33 See Pool, Bollen, Nicolas P.B., "Do Hedge Fund Managers Misreport Returns? Evidence from the Pooled Distribution" (2007) and Abdulali, "The Bias Ratio ${ }^{\mathrm{TM}}$ : Measuring the Shape of Fraud" (2006).

34 Note: We apologize to the reader for the long quotation summarizing Ljungqvist, Malloy, and Marston's results rather than simply summarizing them. Thomson has been quite litigious regarding the issues researched and discussed by Ljungqvist, et al. 
been in the data; and 4) alterations to 10,698 historical recommendation levels. In total, we document 54,729 ex post changes to a database originally containing 280,463 observations. (p. 1). As of February 2007, Thomson Financial's position is that "changes to Recommendation History have occurred as part of necessary processes and maintenance." Previously, Thomson had indicated that the anonymizations were the result of three software glitches. The first produced incorrect start and end dates for some analysts' employment histories. The second caused selective ticker histories for certain analysts to be anonymized, in connection with attempts to consolidate duplicate analyst identifiers. The third, which can still occur, results in recommendations being attributed to an analyst who has departed; subsequent corrections involve anonymizing such recommendations. (fnt. 1 p. 2)

\section{Ljungqvist, Malloy, and Marston (2007) continue:}

"At the recommendation level, the collective effect of the changes is to make the overall distribution of historic recommendations issued for U.S. companies between October 1993 and July 2002 appear more conservative in 2004 than it did in 2002, with considerably fewer strong buys and buys, and more holds, sells, and strong sells." (p. 2)

"Broker-level [data], which can be used to predict the profitability of stock recommendations (Barber et al. (2006)) change even more dramatically. One reason why these findings are important is that the apparently optimistic bias in the historical distribution of recommendations was a frequently cited impetus to the regulatory proceedings that culminated in the Global Research Analyst Settlement of 2003 between New York attorney general Eliot Spitzer, the SEC, NASD, NYSE, North American Securities Administrators Association, state regulators, and twelve brokerage firms." (p. 3) ...

"Similarly, the changes impact the implementation of popular trading strategies based on analyst consensus recommendations. . . A simple trading strategy that buys stocks in the top consensus change quintile and shorts stocks in the lowest quintile each month performs $15.9 \%$ to $42.4 \%$ better on the 2004 tape than on the 2002 tape, suggesting that the changes to the $\mathrm{I} / \mathrm{B} / \mathrm{E} / \mathrm{S}$ database have resulted in the appearance of more profitable analyst research."

"Track records of individual analysts are also affected. . . Among the group of analysts with anonymized recommendations, we find that abnormal returns following subsequently anonymized upgrades-to-buy are significantly lower than are abnormal returns following upgrades by the same analysts that remained untouched. The return differential is large, ranging from $3.6 \%$ to $4.0 \%$ p.a. over the 1993-2002 period. It is even larger in the most recent, post-bubble period (as high as $7.4 \%$ p.a.), and for the sub-sample of bolder recommendations (5.2\% and 9.1\% p.a. in the full-sample and post-bubble periods, respectively)."

"Analysts whose track records are affected are associated with more favorable career outcomes over the 2003-2005 period than their track records and abilities would otherwise warrant. Following the career path modeling in Hong, Kubik, and Solomon (2000) closely, we find that analysts associated with anonymizations experience a more than $60 \%$ increase in the likelihood of subsequently moving from a low-status to a high-status brokerage firm. This effect is much larger than any other in our career outcome models. The magnitude of the effect of additions on career outcomes is also large, boosting the likelihood by more than $40 \%$. Similarly, analysts are more likely to be rated the top stock picker in their sectors by the Wall Street Journal, which relies on Thomson Financial data, if some of their recommendations have been dropped or added."

"Collectively, our findings raise serious doubts about the replicability of past, current, and future studies using the I/B/E/S historical recommendations database." (pp. 3-5) 


\section{COLLUSION BETWEEN ANALYSTS AND FIRMS?} the following:

Hutton's (2004) study of firms' audits of analysts' spreadsheet earnings models result in

Of 421 firms responding to the NIRI 2001 survey, 85.5\% reviewed analysts models (she labeled these "guidance firms"). These analysts showed more accurate forecasts in the sense of lower mean squared errors. But, these analysts' forecasts were systematically downward biased therefore yielding systematic positive earnings surprises.

Analysts of the no-guidance firms walk down their estimated earnings in response to negative earnings surprises (47\% with 3 to 4 quarters of negative earnings news) during the year.

However, analysts of the guidance firms walk down their earnings estimates even though $49 \%$ of the firms have 3 to 4 quarters of positive earnings news. This walkdown gives management a year end boost and indicates a positive beginning-of-year bias. The walk-down practice is consistent with the hypothesis that these analysts ended up issuing forecasts that resulted in systematically positive earnings surprises so as to incur favor with the management team. If this hypothesis is correct, then in return for such positive earnings surprises, analysts receive favors from management that enable them to make more "accurate" (although more biased) forecasts.

Matsumoto (2002) (see Fig. 4 below) and Bartov, Givoly and Hayn (2002) document that the managing earnings game seems to have arisen in the mid-1990s. They find that over the period from 1983-93 to the period 1994-97, the proportion of:

- Negative end-of-quarter earnings surprises fall from $48 \%$ to $31 \%$

- Positive end-of-quarter earnings surprises increase from $40 \%$ to $50 \%$

- Zero earnings surprises increase from $12 \%$ to $19 \%$

- The upward bias in the 1-quarter ahead forecast increased

- A 3\% premium return arose for meeting or beating analyst forecasts at the end of quarter

- A small penalty for negative revisions of forecast during quarter arose 


\section{Fig. 4: The Managing Earnings Game Seems To Have Arisen in the Mid 1990's}

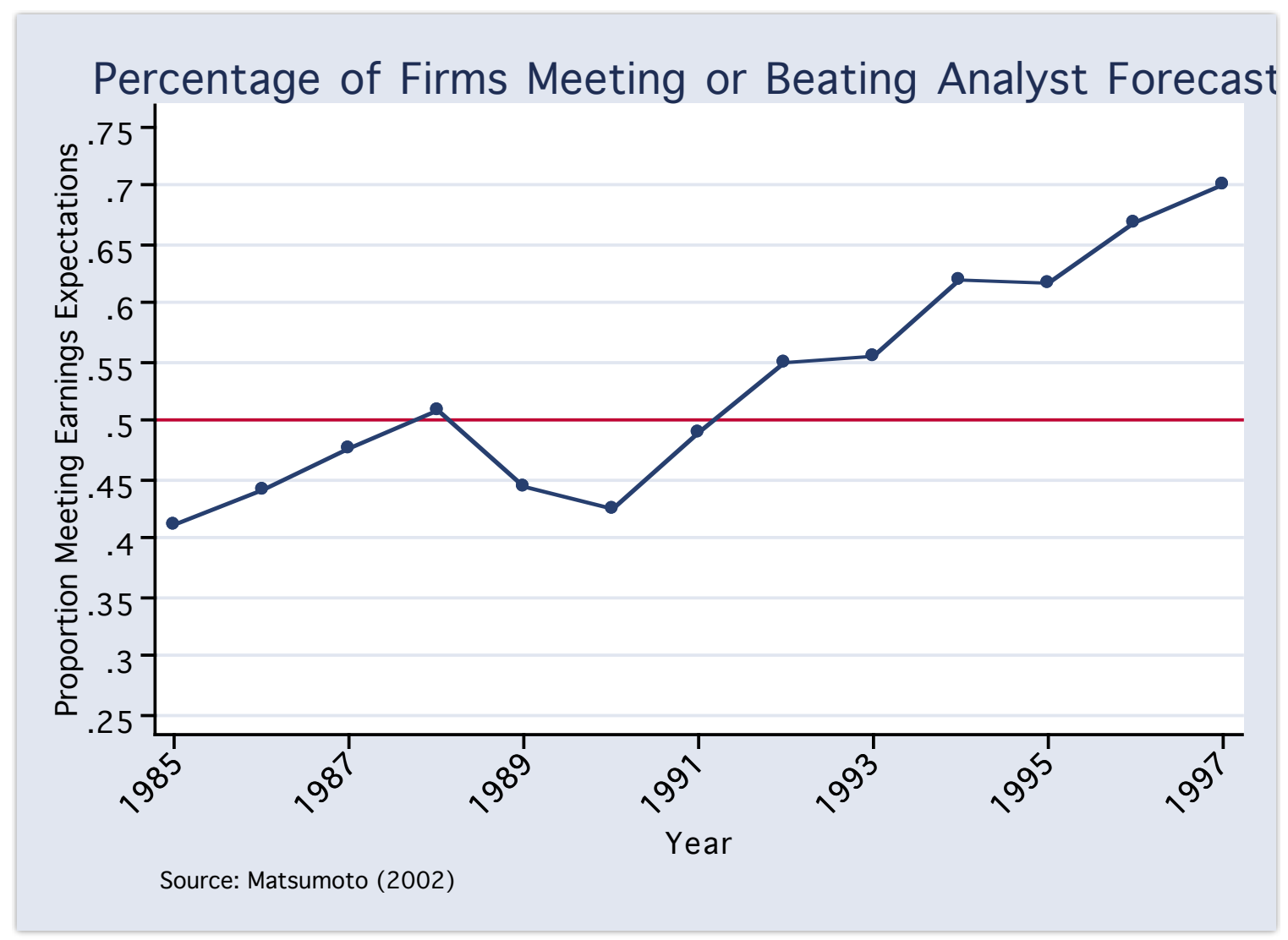

\section{THE PECULIAR EQUILIBRIUM BETWEEN ANALYSTS AND FIRMS}

Analysts long-run (12-month ahead) forecasts are systematically biased high. These forecasts are then walked down so that at the realization date they are systematically low. See Figure 5. In this situation investors appear to get taken (fooled) in both cases (as indicated by the positively biased forecasts at the beginning of the period and the walk down to the negatively biased forecasts at the end of the period). On the face of it this seems highly inconsistent.

One potential hypothesis to explain this inconsistency is that analysts appear to be colluding with managers to allow them to have the benefits of excessively high long-term forecasts while allowing the managers to meet or beat the short-run forecasts at the end of quarter. But it seems impossible for effective collusion to take place amongst so many players. 


\section{Fig. 5: Analysts issue optimistic earnings forecasts and then "walk down" these estimates to a level firms can beat at the official earnings announcement}

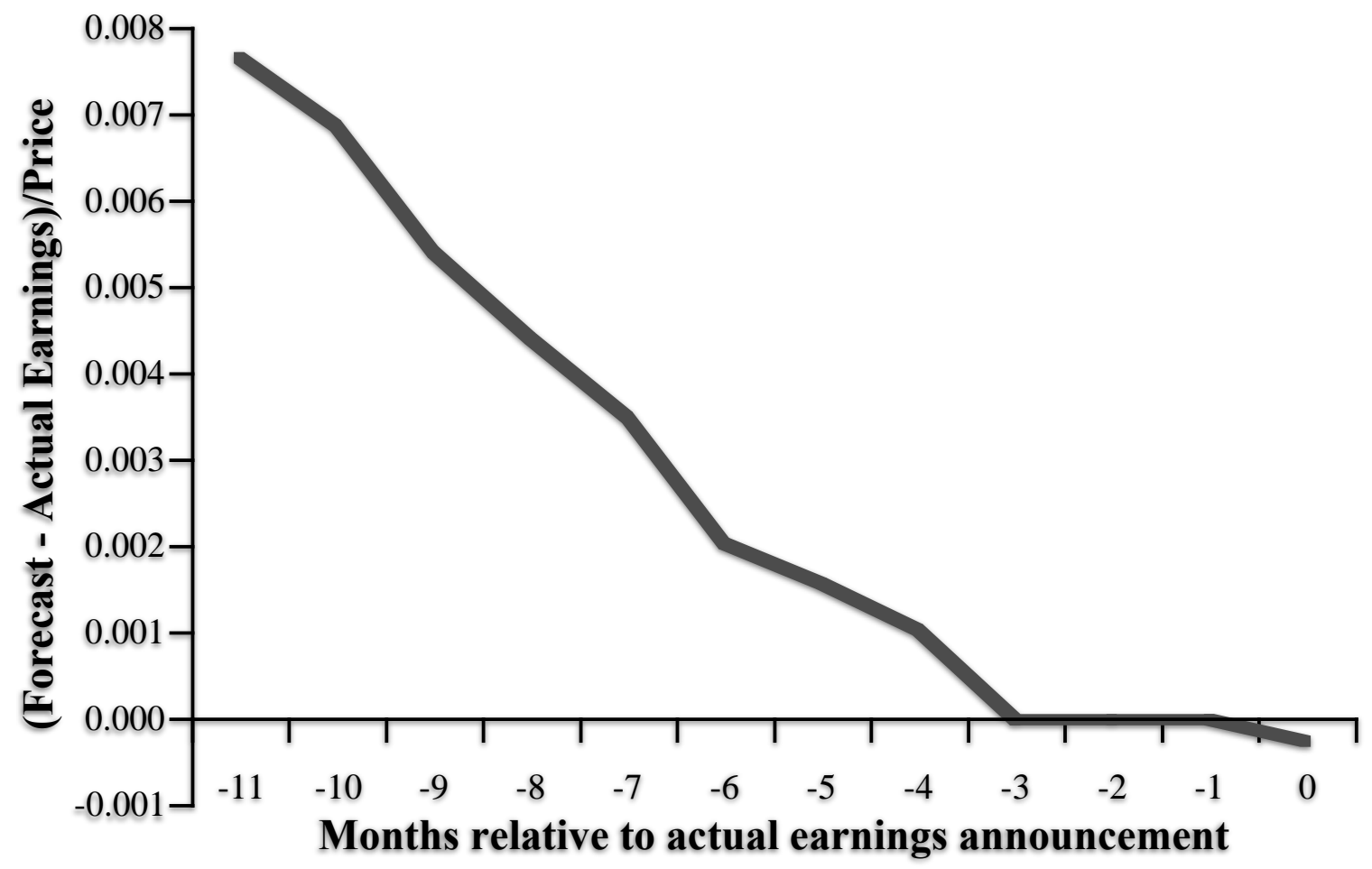

Figure 5 is based on aggregate 1984-2001 data from Richardson, Teoh, and Wysocki (2004) (provided by the authors), and shows the median difference of the forecast earnings per share and actual earnings per share, scaled by the prior-year share price. The sample consists of all individual analyst forecasts for firms with data on both $\mathrm{I} / \mathrm{B} / \mathrm{E} / \mathrm{S}$ and Compustat, and shows that the median consensus analysis forecast is initially positively biased, but that analysts walk down these forecasts each month. By the month of the actual earnings announcement, the median consensus forecast is negatively (and statistically significantly) biased; that is, the median company reports earnings slightly exceeding the year-end analyst forecast.

\section{a. The Walk Down Results from Management Pressure and Analyst Self Selection}

One explanation of this peculiar phenomenon is as follows: Suppose management imposes costs on analysts who are pessimistic (or not sufficiently optimistic) about the future results of the firm. Suppose such analysts opt out of reporting their bad news on companies (without announcing why they opt out), or perhaps they drop their coverage of the firm completly. McNichols and O'Brien (1997) provide an intuitively appealing explanation of this hypothesis and present evidence that the observed phenomenon is not due to analysts making 
systematically biased estimates but rather due to analysts that self-select out of reporting bad news on companies.

If there is a range of analyst opinions about a company in any given month, and the analysts with the most negative opinions or information systematically choose not to offer a report, the resulting consensus opinion (consisting only of analysts who actually report) will be upward biased, even if each reporting analyst is unbiased in his or her opinion.

Analysts with the negative opinions may well opt out of, or delay issuing a recommendation until late in the period (and may drop their coverage of a stock entirely) to avoid the negative repercussions from management and others who are long the stock of the company. It is well known, for example, that analysts seldom issue sell recommendations and frequently delay issuance of reports downgrading a firm. The fact that analysts seldom issue sell recommendations and often delay downgrades of a firm is consistent with this hypothesis. The resulting consensus forecast is then biased upward. ${ }^{35}$ Consistent with this hypothesis, Skinner \& Sloan (2002) conclude: “Analysts' long run EPS forecasts are systematically overoptimistic for growth firms, and ... [this] is systematically related to the inferior stock price performance of growth firms"). See also Dechow, Hutton and Sloan (1999, Abstract) who conclude:

“. . . sell-side analysts' long-term growth forecasts are systematically overly optimistic around equity offerings and that analysts employed by the lead managers of the offerings make the most optimistic growth forecasts. Additionally, we find a positive relation between the fees paid to the affiliated analysts' employers and the level of the affiliated analysts' growth forecasts. We also document that the post-offering under performance is most pronounced for firms with the highest growth forecasts made by affiliated analysts."

These facts are also consistent with a system that is out of integrity and thereby destroys value. In this case the managers that punish analysts who publish accurate but negative (or less positive) forecasts or recommendations are out of integrity because the actions of such managers are not consistent with the expectation (unexpressed request) of holders of the firm's securities that management provide the market with accurate and unbiased financial reports on the firm's performance.

\section{MORE EVIDENCE THAT BOTH MANAGERS AND ANALYSTS MANIPULATE EARNINGS}

- Marquardt and Wiedman (2002) find that managers use accruals to manage earnings either up or down in situations to fit their own interests. At times of equity issues firms use accruals to increase earnings and therefore stock price. In management buyout situations firms use accruals to decrease earnings and therefore stock price.

- The frequency of small quarterly profits is unusually large and the frequency of small losses is unusually small. And so too for small increases and decreases in profits. Burgstahler and Dichev (1997) 
- Managers change real operating decisions such as reducing research and development or advertising expenditures to meet benchmarks. See Dechow and Sloan (1991), Bushee, (1998), Graham, Harvey, and Rajgopal (2005), Rowchowdhury (2004)

- Managers manipulate earnings upward around new equity offerings. Teoh, Welch \& Wong (1998), and Rangan (1998), Darrough \& Rangan (2005)

- Systematically overly optimistic analyst long-term growth forecasts around equity offerings are associated with the largest post IPO under performance. Rajan \& Servaes (1997)

- Myers, Myers and Skinner (2005) find huge numbers of firms with consecutive strings of quarterly EPS non-decreases relative to the expected number. They "find evidence consistent with the hypothesis that managers of sample firms take actions to (i) increase reported EPS when EPS would otherwise decline, and (ii) decrease reported EPS when EPS would otherwise increase by more than necessary to record an increase". Their evidence indicates this is done by strategically reporting special items, strategically timing stock repurchases, and exercising discretion over accounting for taxes to smooth changes in EPS. They conclude: “. . .of all Compustat firms with at least 40 quarters of available data, 811 firms report earnings strings of at least 20 quarters; the corresponding expected [number of firms] varies between 28 and 71, again depending on the [assumed time series] model [generating quarterly earnings]. (p. 16)

\section{IN CONCLUSION}

We argue that the financial economics paradigm is incomplete. The evidence for any paradigm being incomplete is the presence of a significant continuing breakdown in the discipline, along with the discipline's continuing ineffectiveness in dealing with that breakdown (what Kuhn (2012) termed "crises and anomalies" in a discipline). In the world of finance, the combination of 1) the extent of out-of-integrity behavior and its consequent impact on value, coupled with 2) the financial economics discipline having provided little or nothing that has been effective in stemming this out-of-integrity behavior, is evidence for our argument that the financial economics paradigm is incomplete.

The out-of-integrity behavior we termed the "scandals" in Section 2 and the various examples of out-of-integrity behavior discussed in Sections 3 through 10 (mostly unrecognized as out-of-integrity behavior) are important examples of what contributes to the general atmosphere of low integrity in the world of finance (albeit not identified as such and certainly not spoken of). Out-of-integrity behavior has become virtually institutionalized. The environment of low integrity is so pervasive it seems to be nothing more than business as usual, or just a part of the nature of finance. Forstmoser's (2006) first three indicators of the lack of integrity (listed in Section 5.b) "Everyone else is doing it.", "We've always done it.", and "This is the way this business works." illustrate this environment.

When we speak of "integrity", in the case of a system (or object) we mean nothing more than but nothing less than that the design, the implementation of the design, and the use of the system (or 
object) are whole, complete, unbroken, sound, in perfect condition. When we speak of integrity for a person or other human entity, we mean nothing more than but nothing less than that the word (as defined earlier) of the person or other human entity is whole, complete, unbroken, sound, in perfect condition. We have shown that integrity dealt with in this way is an important factor of production.

However, integrity as it is currently understood has been undistinguished as a factor of production, with the result that its effect on workability, and therefore productivity and value (by its presence or absence) has been wrongfully assigned to other causes. Integrity, as we define it, matters. Not because it is virtuous, but because it creates workability. And workability increases the opportunity for performance, and maximum workability is necessary for realizing maximum value. Note that describing the effects of integrity is not normative. In addition, we make no admonition to act with integrity; it doesn't work to tell people what to do. We don't tell people what to do, rather we give a picture of reality (in this case of the reality of integrity revealed as a positive phenomenon) that naturally alters their correlated behavior.

As the Law of Integrity states: As the integrity (the state of being whole and complete, etc.) of an object, system, person, or other human entity or practice declines, workability declines, and as workability declines the opportunity for performance declines. Note however that when the behavior is not recognized as out of integrity, the decline in the opportunity for performance will be explained in some other way.

The model of integrity introduced in this paper makes clear just how widespread out-ofintegrity behavior actually is, and the enormity of the cost of out-of-integrity behavior. The model also makes clear that given the way integrity is currently understood, our out-of-integrity behavior does not occur for us as such, and as a result we ascribe the cause of the damage of outof-integrity behavior to something other than our out-of-integrity behavior. But the recognition of the foregoing is only a beginning for persons, groups, and organizations to have access to acting with integrity.

From within our new model of integrity when it is fully understood, integrity occurs for people (is understood by people, shows up for people) such that 1) out-of-integrity behavior actually shows up for people as out-of-integrity behavior, but most importantly, 2) the damaging consequences of that behavior, whether immediate or long term, show up in present time right along with the behavior, and 3) the damaging consequences show up as being caused by the behavior. This profoundly alters the way out-of-integrity behavior occurs or shows up for people. As we have said, people with normal brains act in what appears to them to be in their self interest, but in their self interest given the way in which what they are dealing with occurs or shows up for them.

Our purpose here has been to show that including integrity as a purely positive phenomenon, and as such an important factor of production in the paradigm of financial economics, would allow financial economics' scholars to develop the tools to effectively deal with the "crises and anomalies" of the value destroying out-of-integrity behavior in the world of finance, and ultimately to transform the culture of finance to be one of integrity.

What makes this addition to the current financial economics paradigm challenging for most professionals is that the "proof" of a paradigm is the "testing" of it in practice, rather than in the a priori theoretical proof of it. While the proposition that "as integrity (whole and 
complete) decreases, workability decreases" is unmistakably valid, the proposition that "any diminution in the integrity (wholeness and completeness) of an individual's or other human entity's word results in a diminution of workability for that individual or entity" is a heuristic. It just works. When that it actually works in practice becomes a clear-cut personal discovery, that naturally alters future behavior.

\section{APPENDIX 1: A CONTINUING SERIES OF SCANDALS IN FINANCE}

There has been a continuing stream of scandals in the financial sector in the last 10 years (all involving out-of-integrity behavior) that has imposed huge costs on the entities that have been the source of the out-of-integrity behavior as well as other organizations and individuals who were merely customers, associates, or bystanders in these events. These continuing scandals have played a non-trivial role in the world-wide decline in business conditions, steep financial losses in the private sector, massive government bailouts of financial institutions and continuing high unemployment in many areas of the world. What follows is an iincomplete listing and brief description of some of the major recent scandals.

\section{a. The Goldman Sachs Abacus 2007-AC1 Mortgage Backed Securities}

In 2007 Goldman Sachs created its Abacus 2007-AC1 \$2 billion Synthetic CDS (credit default swap) issue of mortgage backed securities product in which the actual mortgage securities incorporated in Abacus were selected by Paulson and Company who intended to short the securities. The pitch book indicated the securities in the vehicle were selected by ACA Capital which had contracted to manage the vehicle. Paulson and Company paid millions of dollars to Goldman to create the vehicle so Paulson could sell it short.

The majoriity of the mortgages in the deal defaulted within six months of its issue, leading to billions of dollars in losses to clients that Goldman sold the deal to. On July 15, 2010 Goldman paid a then record \$550 million to settle SEC charges related to the Abacus subprime mortgage CDS and acknowledged that Goldman should have revealed Paulson's role in selecting the securities in the deal. See Securities and Exchange Commission (2011) for details on the settlement. Importantly, Goldman's actions in this case violated 7 of Goldman's 13 business principles as they are published on Goldman's web site. ${ }^{36}$ Note these principles are formally Goldman's word to its clients, employees and others.

\section{b. JP Morgan Chase \& Co. Sued on Mortgage Backed Securities}

The New York attorney general filed suit in NY state court alleging widespread fraud in the packaging and sale of mortgage backed securities that failed generating $\$ 22.5$ billions of losses to the investors in those securities issued by Bear Stearns \& Company in 2006 and 2007 before Bear nearly collapsed and was taken over by JP Morgan.

36 See the Appendix to the following talk (Erhard and Jensen 2011, "A Value-Free' Approach to Values" at http://ssrn.com/abstract=1640302 ) for a discussion of the Goldman Sachs Abacus 2007-AC1 CDS mortgage backed securities fiasco. 
"The lawsuit quotes from emails and messages purportedly sent within Bear Stearns that it says showed the bank was aware it was selling poor quality investments. In one, a Bear Stearns employee described one securitization in an internal email as a "sack of s***," according to the lawsuit." 37

The suit argues that Bear Stearns knew these mortgage backed securities would fail and indeed, the losses on the mortgage-backed securities were "astounding", totaling more than $25 \%$ of the original principal balance. The suit asks that the company be made to pay damages "caused, directly or indirectly, by the fraudulent and deceptive acts."

This conflict is remarkably similar to the difficulties created by Goldman Sachs in the structuring and sale of the Abacus mortgage backed securities discussed directly above. in Section 4.b in the text.

\section{c. The Bernard Madoff Ponzi Scheme}

On Dec. 10, 2008 Bernard Madoff admitted to his sons that the asset management arm of his firm was a Ponzi Scheme. "On March 12, 2009, Madoff plead guilty to 11 federal crimes, including securities fraud, wire fraud, mail fraud, money laundering, perjury, and falsifying files with the SEC. Refusing to name accomplices, he claimed sole responsibility for the Ponzi scheme and defrauding his clients of $\$ 65$ billion. ... Former SEC Chairman Harvey Pitt estimated the actual net fraud to be between $\$ 10$ and $\$ 17$ billion. (Note this calculation does not include the fictional returns Madoff credited to his customer accounts.) Prosecutors identified $\$ 13.2$ billion in losses in accounts opened since 1996." 38 He was sentenced to 150 years in prison. Interestingly, Madoff was Chairman of the Board of Directors and on the Board of Governors of the National Association of Securities Dealers (NASD).

\section{d. HSBC Violation of Money Laundering Laws}

In December, 2012 HSBC, the global UK bank agreed to pay a record \$1.9 billion in U.S. penalties for violations of money laundering laws in its dealings with various questionable and criminal enterprises.

"The Department of Justice and U.S. Treasury said Tuesday that HSBC allowed the most notorious international drug cartels to launder billions of dollars across borders. In addition, the government said HSBC violated U.S. sanctions for years by illegally conducting transactions on behalf of customers in Iran, Libya, Cuba, Sudan and Burma.

At a news conference in Brooklyn, N.Y., Assistant Attorney General Lanny Breuer said the settlement concluded a five-year investigation in which the department reviewed 9 million documents.

"HSBC is being held accountable for stunning failures of oversight," said Breuer in a department statement. "The record of dysfunction that prevailed at HSBC for many years

$37 \quad$ Eaglesham and Fitzpatrick (2012)

38 Source: Jewish Virtual Library: Bernard Madoff. Accessed Feb 26, 2013. 
was astonishing."

HSBC CEO Stuart Gulliver accepted responsibility for the banks' mistakes. "We have said we are profoundly sorry for them, and we do so again," Gulliver said in a statement.

The deal includes a deferred prosecution agreement with the Department of Justice. No charges will be brought against the bank provided certain conditions are met. Breuer didn't rule out individual prosecutions.

As part of the settlement, HSBC is required to take actions to strengthen its compliance policies and procedures. HSBC has also replaced its senior management, and "clawed back" deferred compensation bonuses given to its most senior officers in the money laundering compliance division. ... .

In Mexico, HSBC became the preferred bank for drug cartels and money launderers, according to the Justice Department. The government said the bank didn't raise red flags even when billions of dollars in transactions took place in cash, the typical mode of operation for drug dealers.

Between 2006 and 2009, according to DOJ, HSBC failed to monitor \$670 billion in wire transfers and $\$ 9.4$ billion in cash transactions from its Mexico bank operations.

Because of these failures, at least $\$ 881$ million in drug trafficking money -- including those of the Sinaloa Cartel of Mexico and the Norte del Valle Cartel of Colombia -- were laundered through HSBC, according to Justice.

The DOJ said HSBC also helped process $\$ 660$ million in prohibited transactions from Iran, Cuba, Sudan, Libya and Burma by deliberately hiding the identities of these countries.

\section{Record fines: 'New normal' for banks?}

The London-based bank joins a long list of financial institutions that have faced scrutiny from U.S. regulators over allegedly illicit money transfers, but the size of its combined settlement with eight different U.S. authorities is unprecedented.

U.K. bank Standard Chartered agreed Monday to pay \$327 million to settle charges that it violated international sanctions on transactions with Iran, Burma, Libya and Sudan.

In June, Dutch bank ING agreed to pay a \$619 million penalty for moving billions of dollars through the U.S. financial system at the behest of Cuban and Iranian clients.

Back in 2010, Wachovia Bank paid \$160 million to resolve allegations that its weak internal controls allowed Mexican cartels to launder millions of dollars worth of drug proceeds. Wells Fargo bought Wachovia in 2008.

And Swiss bank Credit Suisse paid \$536 million in 2009 to settle U.S. claims concerning business with Iran and other countries. 
While HSBC's penalty dwarfs these other settlements, it's still just a fraction of the $\$ 16.8$ billion in profits the bank recorded globally last year. ${ }^{39}$

"As part of the agreement, the bank will admit to violating the Bank Secrecy Act, the Trading with the Enemy Act and other U.S. laws intended to prohibit money laundering, a government official said." ...

"The report by the Senate Permanent Subcommittee on Investigations detailed a regulatory culture at HSBC that shocked even its own employees, according to testimony provided to the committee and at a hearing.

"Senate investigators concluded HSBC did little to clean up operations that should have raised concerns. HSBC's Mexico bank had a branch in the Cayman Islands that had no offices or staff but held 50,000 client accounts and \$2.1 billion in 2008, the report said.

"What is this, the School of Low Expectations Banking?" one HSBC Latin America compliance official wrote in a complaint about the practices at HSBC Mexico, according to the Senate report. The HSBC official said the Mexico bank's antimoney-laundering committee 'can't keep rubber-stamping unacceptable risks because someone on the business side writes a nice letter....We have seen this movie before, and it ends badly.' "

In 2010 Wachovia Bank paid \$160 million to settle similar Justice Department charges. ${ }^{40}$

\section{e. Manipulation and Rigging of the LIBOR Interest Rate Benchmark}

LIBOR is the London Interbank Offered Rate. This interest rate, set by submissions of borrowing rates by a dozen banks, plays a major role in determining the interest rate on " $\$ 750$ trillion worth of financial products, including mortgages, credit cards and student loans as well as to set the prices of vast amounts of derivatives being traded."41

The New York Times (2013) reports that:

"In 2012, Libor became the center of one of the biggest financial scandals in recent years, as investigators in the United States and Britain focused on possible criminal wrongdoing by a number of the world's biggest banks over the manipulation of Libor. Questions have also been raised about the failure of regulators in both countries to stop the practice, despite evidence that both the Bank of England and the Federal Reserve of New York were aware of it.

The scandal came to light in late June 2012, when Barclays, the British financial giant, agreed to pay $\$ 450$ million to settle accusations by American and British authorities that some of its traders attempted to manipulate Libor rates to bolster profits. Authorities also accused Barclays of submitting low rates to deflect concerns about its health during the financial crisis. The scandal prompted the resignations of top bank officials, including the

\footnotetext{
39 O'Toole and Riley (2013)

$40 \quad$ Barrett and Perez (2012).

$41 \quad$ New York Times (2013)
} 
chief executive, Robert E. Diamond Jr.”

Protess and Scott (2012) report that: "In the Barclays case, regulators say they uncovered "pervasive" wrongdoing that spanned a four-year period and touched top rungs of the firm, including members of senior management and traders stationed in London, New York and Tokyo. A 45-page complaint laid bare the scheme that unfolded from 2005 to 2009, describing how Barclays had made false reports with the aim of manipulating rates to increase the bank's profits. Barclays was also accused of "aiding attempts by other banks to manipulate" Euribor. ...

The practice of submitting false numbers prompted unease among some employees, who worried the bank was "being dishonest by definition." ...

Amid speculation that the bank was struggling to raise money, Barclays' senior management asked employees to lower the rates submitted to the Libor committee, according to the regulatory filings. Management wanted the bank's rates in line with rivals. Senior Barclays executives instructed employees not to put your "head above the parapet." Some employees resisted, but eventually followed orders from top executives, according to regulatory documents. One concerned employee called the rates "patently false."

On July 1, 2012 The Telegraph ${ }^{42}$ newspaper published an article authored by an employee at a large British bank (not Barclays) entitled: "Libor scandal: How I Manipulated the Bank Borrowing Rate". The Telegraph's introduction to the article is as follows:

"An anonymous insider from one of Britain's biggest lenders - aside from Barclays explains how he and his colleagues helped manipulate the UK's bank borrowing rate. Neither the insider nor the bank can be identified for legal reasons."

In the insider's own words, he goes on to explain as follows:

"It was during a weekly economic briefing at the bank in early 2008 that I first heard the phrase. A sterling swaps trader told the assembled economists and managers that "Libor was dislocated with itself". It sounded so nonsensical that, at first, it just confused everyone, and provoked a little laughter.

Before long, though, I was drawing up presentations to explain the "dislocation of Libor from itself" for corporate relationship managers. I was deciphering the subject in emails, internally and externally. And I was using the phrase myself openly with customers of the bank.

What I was explaining was that the bank was manipulating Libor. Only I didn't see it like that at the time.

What the trader told us was that the bank could not be seen to be borrowing at high rates, so we were putting in low Libor submissions, the same as everyone. How could we do 
that? Easy. The British Bankers' Association, which compiled Libor, asked for a rate submission but there were no checks. The trader said there was a general acceptance that you lowered the price a few basis points each day.

According to the trader, "everyone knew" and "everyone was doing it". There was no implication of illegality. After all, there were 20 to 30 people in the room - from management to economists, structuring teams to salespeople - and more on the teleconference dial-in from across the country.

The discussion was so open the behaviour seemed above board. In no sense was this a clandestine gathering.

Looking back, I now feel ashamed by my naivety. Had I realized what was going on, I would have blown the whistle. But the openness alone suggested no collusion or secrecy. Management had been in the meeting, and so many areas of the Treasury division of the bank represented, that this was clearly no surprise or secret."

As an aside, please note in this excellent example how the "occurring" shaped how the situation showed up for this person - how a patently illegal act showed up as something that was perfectly honest and upstanding. And as we have said, when the occurring shifts behavior shifts to be consistent with it.

In December of 2012, the Swiss bank UBS, paid record total fines of $\$ 1.5$ billion "for its role in a multiyear scheme to manipulate interest rates", its Japanese subsidiary plead guilty to a charge of felony wire fraud, and the Justice Department "filed criminal charges against two former UBS traders". On December 19, 2012 Mark Scott and Ben Protess (2012) writing for DealBook reported the following:

"The cash penalties represented the largest fines to date related to the rate-rigging inquiry. The fine is also one of the biggest sanctions that American and British authorities have ever levied against a financial institution, falling just short of the $\$ 1.9$ billion payout that HSBC made last week over money laundering accusations.

The severity of the UBS penalties, authorities said, reflected the extent of the problems. The government complaints laid bare a scheme that spanned from at least 2001 to 2010, describing how the bank reported false rates to squeeze out extra profits and deflect concerns about its health during the financial crisis. The Commodity Futures Trading Commission, the American regulator leading the case, cited more than 2,000 instances of illegal acts involving dozens of UBS employees.

"The findings we have set out in our notice today do not make for pretty reading," Tracey McDermott, enforcement director for the Financial Services Authority of Britain, said in a statement. "The integrity of benchmarks," she said, "are of fundamental importance to both U.K. and international financial markets. UBS traders and managers ignored this."

The UBS case reflects a pattern of abuse that authorities have uncovered as part of a 
multi-year investigation into rate-rigging. The inquiry, which has ensnared more than a dozen big banks, is focused on key benchmarks like the London interbank offered rate, or Libor.. ${ }^{43}$

The New York Times (2013) reports: "Canadian, Swiss and Asian authorities as well as the Justice Department, the Commodity Futures Trading Commission and Britain's Financial Services Authority are investigating more than a dozen banks. Along with UBS, the futures commission was focused on potential wrongdoing at two American banks, Citigroup and JPMorgan Chase, officials said. HSBC was also under scrutiny."

"As the Justice Department announced its case against UBS, prosecutors also took aim at two former UBS traders at the center of the rate-rigging scheme . . . the Justice Department charged Tom Hayes and Roger Darin with conspiracy to commit wire fraud. Mr. Hayes also faces an additional count of wire fraud and another related to price fixing. "By causing UBS and other financial institutions to spread false and misleading information," Attorney General Eric Holder said in a statement, "these alleged conspirators - and others at UBS - manipulated the benchmark interest rate upon which many consumer financial products - including credit cards, student loans, and mortgages - are frequently based. ${ }^{44}$

J.R. (2013) Writing for the Dec. 19, 2012 Economist column, "Schumpter: Business and Management" summarizes some of what was unfolding in the manipulation of LIBOR and EURIBOR interest rates in his column entitled "Horribly Rotten, Comically Stupid" as follows:

"For any who doubted whether there was honour among thieves, or indeed among investment bankers, solace may be found in the details of a settlement between UBS, a Swiss bank, and regulators around the world over a vast and troubling conspiracy by some of its employees to rig LIBOR and EURIBOR, key market interest rates. Regulators in Britain and Switzerland have argued that manipulation of interest rates that took place over a long period of time, involved many employees at UBS and that, according to Britain's Financial Service Authority, was so "routine and widespread" that "every LIBOR and EURIBOR submission, in currencies and tenors in which UBS traded during the relevant period, was at risk of having been improperly influenced to benefit derivatives trading positions."

Yet, even in the midst of this wrongdoing there was evidence of a sense of honour, however misplaced. One banker at UBS, in asking a broker to help manipulate submissions, promised ample recompense:

43 Scott and Protess (2012)

44 Dealbook (2012), http://dealbook.nytimes.com/2012/12/19/2-former-ubs-traders-exposed-in-raterigging-case/ 
"I will ... do one humongous deal with you ... Like a 50,000 buck deal, whatever. I need you to keep it as low as possible ... if you do that ... I'll pay you, you know, 50,000 dollars, 100,000 dollars ... whatever you want ... I'm a man of my word."

Further hints emerge of the warped morality that was held by some UBS employees and their conspirators at brokers and rival banks. In one telling conversation an unnamed broker asks an employee at another bank to submit a false bid at the request of a UBS trader. Lest the good turn go unnoticed the broker reassures the banker that he will pass on word of the manipulation to UBS.

Broker B: "Yeah, he will know mate. Definitely, definitely, definitely";

Panel Bank 1 submitter: "You know, scratch my back yeah an all"

Broker B: "Yeah oh definitely, yeah, play the rules."

"Regulators found that brokers at these firms helped coordinate false submissions between banks, posted false rates and estimates of where rates might go on their own trading screens, and even posted spoof bids to mislead market participants as to the real rate in the market."

In addition, in early 2013 the Royal Bank of Scotland (RBS) was fined \$612 million by regulators for manipulating the Libor Rate. ${ }^{45}$ And in 2012 the attorneys general of New York and Connecticut issued subpoenas to Citigroup, Deutsche Bank, JPMorgan Chase and HSBC and it has yet to be seen what comes from those investigations. ${ }^{46}$

Interestingly there are indications that the manipulation of LIBOR was going on as early as 1991, and attempts to call attention to that manipulation were ignored by the authorities. See Douglas (2012).

\section{f. "BofA Probed by New York Over Mortgage Securities"}

"Bank of America Corp., the second- biggest U.S. bank by assets, is under investigation by the New York Attorney General's Office over the bundling of mortgage loans into securities.

New York Attorney General Eric Schneiderman, who sued JP Morgan Chase \& Co. last year over losses on mortgage bonds, is probing the purchase, securitization and underwriting of home loans and mortgage securities, the bank said yesterday in a regulatory filing. ${ }^{47}$

The bank, based in Charlotte, North Carolina, said it "continues to cooperate fully" with the investigation. The U.S. Securities and Exchange Commission is investigating practices by the bank's Merrill Lynch unit related to collateralized debt obligations, including valuation and marketing, according to the filing.

$45 \quad$ Finch, Fortado and Brush (2013)

$46 \quad$ Forbes (2012)

$47 \quad$ McLaughlin (2013) 
Schneiderman is the co-chairman of a state and federal group established last year to investigate misconduct in the mortgage-securities market. The group includes the U.S. Justice Department and the SEC. 


\section{REFERENCES}

Abdulali, Adil, 2006. The Bias Ratio ${ }^{\mathrm{TM}}$ : Measuring the Shape of Fraud (Protégé Partners, New York).

Agarwal, Vikas, Daniel, Naveen D. and Naik, Narayan Y., Do Hedge Funds Manage Their Reported Returns? (November 15, 2010). The Review of Financial Studies, Forthcoming. Available at SSRN: http://ssrn.com/abstract=891169

Aggarwal, Rajesh K., Laurie Krigman, and Kent L. Womack. 2002. "Strategic IP Underpricing, Information Momentum, and Lockup Expiration Selling." Journal of Financial Economics, V. 66, No. 1: pp 105-137.

Anand, "Harmed Investor? Just Wait - Brokerage Firms Pay \$255 Million, but Getting It Takes Time," Wall Street Journal (2006)

Argyris, Chris. 1991. Teaching Smart People How to Learn. Harvard Business Review: MayJune

Barrett, Devlin, and Evan Perez, HSBC to Pay Record U.S. Penalty: U.K.-Based Bank Expected to Admit Money-Laundering Lapses as Part of \$1.9 Billion Agreement, Wall Street Journal (2012) http://online.wsj.com/article/SB10001424127887324478304578171650887467568.html?KE YWORDS=HSBC+Money+laundering (Accessed Feb 25, 2013)

Bartov, Eli, Givoly, Dan and Hayn, Carla, "The Rewards to Meeting or Beating Earnings Expectations" (October 2000). Available at SSRN: $\underline{\text { http://ssrn.com/abstract=247435 }}$

Bird, Alexander, "Thomas Kuhn", The Stanford Encyclopedia of Philosophy (Winter 2011 Edition), Edward N. Zalta (ed.), 4.2 Perception, Observational Incommensurability, and World Change, URL $=<$ http://plato.stanford.edu/archives/win2011/entries/thomas-kuhn/>

Bodnaruk, Andriy, Massa, Massimo and Simonov, Andrei, "The Dark Role of Investment Banks in the Market for Corporate Control" (December 2007). EFA 2007 Ljubljana Meetings Paper, http://www.econ.upf.edu/docs/seminars/bodnaruk.pdf

Brunnermeirer, Markus K. "Deciphering the Liquidity and Credit Crunch 2007-2008, Journal of Economic Perspectives, V. 23, No. 1, Winter 2009, pp. 77-100.

Bradshaw, Mark T., Scott A. Richardson, and Richard G. Sloan. 2005. "The Relation between Corporate Financing Activities, Analysts' Forecasts and Stock Returns". In Journal of Accounting and Economics Conference, 2004.

Burgstahler, D., and I. Dichev. 1997. Earnings management to avoid earnings decreases and losses. Journal of Accounting \& Economics 24 (December): 99-126. 
Bushee, Brian. 2004. "Identifying and Attracting the "Right" Investors: Evidence on the Behavior of Institutional Investors." Journal of Applied Corporate Finance, V. 16, No. 4: Fall, pp. 28-35.

Burton, Jonathan, 2003, Fund Roundup: A review of the firms implicated so far in trading scandal, Wall Street Journal, Market Watch (Dow Jones).

Clement, Michael B. 1999. "Analyst Forecast Accuracy: Do Ability, Resources, and Portfolio Complexity Matter?" Journal of Accounting and Economics, V. 27, No. 3: pp 285-303.

Cowen, Amanda, Groysberg, Boris and Healy, Paul M., "Which Types of Analyst Firms Make More Optimistic Forecasts?" (July 8, 2003). Harvard NOM Working Paper No. 03-46. http://ssrn.com/abstract $=436686$

Darrough, Masako, and Rangan, Srinivasan, Do Insiders Manipulate Earnings When They Sell Their Shares in an Initial Public Offering?, Journal of Accounting Research, Vol. 43 No. 1 March 2005, pp. 1-33.

Dealbook, “Goldman Settles With S.E.C. for \$550 Million”, July 15, 2010. http://dealbook.nytimes.com/2010/07/15/goldman-to-settle-with-s-e-c-for-550-million/ (accessed March 3, 2013)

Dealbook, "2 Former UBS Traders Exposed in in Rate-Rigging Case" http://dealbook.nytimes.com/2012/12/19/2-former-ubs-traders-exposed-in-rate-rigging-case/ (accessed Feb 25, 2013)

Dechow, Patricia M., Hutton, Amy P. and Sloan, Richard G., "The Relation between Analysts' Forecasts of Long-Term Earnings Growth and Stock Price Performance Following Equity Offerings" (June 1999). http://ssrn.com/abstract=168488

Dealbook, "Goldman Settles With S.E.C. for \$550 Million”, July 15, 2010. http://dealbook.nytimes.com/2010/07/15/goldman-to-settle-with-s-e-c-for-550-million/ (accessed March 3, 2013)

Degeorge, François, Jayendu Patel and Richard Zeckhauser. 1999. "Earnings Management to Exceed Thresholds." Journal of Business, V. 72, No. 1: pp. 1-33.

Douglas, Keenan, "My Thwarted Attempt To Tell of Libor Shenanigans" Financial Times, July 27, 2012. Manipulation w http://www.informath.org/media/a72/b1.pdf and http://www.informath.org/media/a72/b3.htm

Dyson, Freeman. 2011. "How to Dispel Your Illusions". Review of Thinking, Fast and Slow, by Daniel Kahneman. The New York Review of Books, 22 December. Accessed 6 February, 2012. http://www.nybooks.com/articles/archives/2011/dec/22/how-dispel-your-illusions/ 
Eaglesham, Jean, and Dan Fitzpatrick. (October 1, 2012). J.P. Morgan Sued on Mortgage Bonds," Wall Street Journal, http://online.wsj.com/article/SB10000872396390444138104578030903731665328.html (accessed March 3, 2013)

Erhard, Werner and Jensen, Michael C., A Positive Theory of the Normative Virtues (December 7, 2011). Harvard Business School NOM Unit Working Paper No. 12-007; Barbados Group Working Paper No. 11-06. Available at SSRN: http://ssrn.com/abstract=1906328

Erhard, Werner, Jensen, Michael C. and Granger, Kari L., Creating Leaders: An Ontological/Phenomenological Model (July 5, 2012). THE HANDBOOK FOR TEACHING LEADERSHIP, Chapter 16, Scott Snook, Nitin Nohria, Rakesh Khurana, eds., Sage Publications, 2011; Harvard Business School NOM Unit Working Paper 11-037; Barbados Group Working Paper No. 10-10; Simon School Working Paper Series No. FR 10-30. Available at SSRN: http://ssrn.com/abstract=1681682

Erhard, Werner, Jensen, Michael C. and Barbados Group, A New Paradigm of Individual, Group, and Organizational Performance (November 17, 2010). Harvard Business School NOM Unit Working Paper No. 11-006; Barbados Group Working Paper No. 09-02. Available at SSRN: http://ssrn.com/abstract=1437027

Erhard, Werner, Jensen, Michael C. and Zaffron, Steve, Integrity: A Positive Model that Incorporates the Normative Phenomena of Morality, Ethics and Legality (March 23, 2009). Harvard Business School NOM Working Paper No. 06-11; Barbados Group Working Paper No. 06-03; Simon School Working Paper No. FR 08-05. Available at SSRN: http://ssrn.com/abstract=920625

Erhard, Werner, Jensen, Michael C. and Zaffron, Steve, Integrity: A Positive Model that Incorporates the Normative Phenomena of Morality, Ethics, and Legality - Abridged (English Language Version) (March 7, 2010). Harvard Business School NOM Unit Working Paper No. 10-061; Barbados Group Working Paper No. 10-01; Simon School Working Paper No. 10-07. Available at SSRN: http://ssrn.com/abstract=1542759

Erhard, Werner and Jensen, Michael C., Putting Integrity into Finance: A Purely Positive Approach (January, 15 2012). Available at SSRN: http://ssrn.com/abstract=1985594

Finch, Gavin, Lindsay Fortado and Silla Brush, "RBS Fined $\$ 612$ million by regulators for Manipulating Libor Rate”, Bloomberg, (Feb. 6, 2013) http://www.bloomberg.com/news/2013-02-05/rbs-said-to-face-up-to-783-million-fine-formanipulating-libor.html (Accessed March 3, 2013)

Fireman, Paul: "Commencement Address to the Suffolk University Sawyer Business School”, May $19^{\text {th }}, 2013$, Boston, Massachusetts, http://www.youtube.com/watch?gl=US\&hl=en\&client=mv-google\&v=lTw0GX4nVXs\&nomobile=1 (Accessed February 28, 2014) 
Forbes, "7 Banks Hit With libor Subpoenas Courtesy of NY Attorney General Schneiderman" (Agust 15, 2012) http://www.forbes.com/sites/halahtouryalai/2012/08/15/7-banks-hit-withlibor-subpoenas-courtesy-of-ny-attorney-general-schneiderman/ (Accessed March 3, 2013)

Forstmoser, Peter. "Integrity in Finance” (speech given to Swiss Banking Institute, 11-15-2006)

Fuller, Joseph and Jensen, Michael C., "Just Say No To Wall Street". Journal of Applied Corporate Finance, Vol. 14, No. 4 (Winter 2002) pp. 41-46. http://ssrn.com/abstract=297156

Goldstein, Noah J., Steven J. Martin, Robert B. Cialdini. 2007. Yes! 50 Secrets From The Science Of Persuasion. London: Profile Books.

Graham, Harvey \& Rajgopal survey "Economic Implications of Corp. Fin. Reporting" http://ssrn.com/abstract=491627

Harsanyi, John C. 1953. "Cardinal Utility in Welfare Economics and in the Theory of RiskTaking”. Journal of Political Economy 61: 434-435.

Harsanyi, John C. 1955. "Cardinal Welfare, Individualistic Ethics, and Interpersonal Comparison of Utility”. Journal of Political Economy 63: 309-321.

Hayn, C. 1995. The information content of losses. Journal of Accounting \& Economics 20 (September): 125-153.

Hayward, Mathew L. A. and Warren Boeker. 1998. "Power and Conflicts of Interest in Professional Firms: Evidence from Investment Banking." Administrative Science Quarterly, V. 43, No. 1 (Mar., 1998): pp 1-22.

Healy, Paul M. 1985. "The Effect of Bonus Schemes on Accounting Decisions." Journal of Accounting \& Economics, V. 7, No. 1-3: pp. 85-107.

Healy, Paul M., and Krishna Palepu.'Information Asymmetry, Corporate Disclosure and the Capital Markets: A Review of the Empirical Disclosure Literature" (December 2000). JAE Rochester Conference April 2000. http://ssrn.com/abstract=258524

Healy, P. M., and J. M. Wahlen. 1999. A review of the earnings management literature and its implications for standard setting. Accounting Horizons 13 (December): 365-383.

Hong, Harrison and Jeffrey D. Kubik. 2003. "Analyzing the Analysts: Career Concerns and Biased Earnings Forecasts." The Journal of Finance, V. 58, No. 1: pp 313-351. http://www.blackwell-synergy.com/loi/jofi

Hutton (1999) The Relation Between Analysts' Earnings Forecasts of Long-Term Earnings Growth and Stock Price Performance Following Equity Offerings http://ssrn.com/abstract=168488 
Hutton, Amy, 2004. Determinants of Managerial Earnings Guidance Prior to Regulation Fair Disclosure and Bias in Analysts Earnings Forecasts, http://ssrn.com/abstract=567441

Hutton, Amy. 2004. "Beyond Financial Reporting — An Integrated Approach to Disclosure." Journal of Applied Corporate Finance, V. 16, No. 4: Fall, pp. 8-16.

Hutton, Amy, and James Weber, 2001, Progressive Insurance: Disclosure Strategy, Harvard Business School Case, 9-102-012, December 12.

Isberg, Steven C., Tomas Thundiyil and Rob Owen, 2012. "Integrity and Learning: Enhancing Workability and Student Performance Outcomes," by Steven C. Isberg, Tomas Thundiyil, and Rob Owen, unpublished manuscript, http://ssrn.com/abstract=2148783

Jacob, John, Thomas Z. Lys, and Margaret A. Neale. 1999. "Experience in Forecasting Performance of Security Analysts." Journal of Accounting and Economics, V. 28: pp 51-82.

Jensen, Michael C., "Paying People to Lie: The Truth About the Budgeting Process" (Revised September, 2001). Harvard NOM Research Paper No. 01-03, and HBS Working Paper No. 01-072, European Financial Management, Vol. 9, pp. 379-406, September 2003 http://ssrn.com/abstract=267651

Jensen, Michael C., Corporate Budgeting Is Broken, Let's Fix It. Harvard Business Review, pp. 94-101, November 2001. Available at SSRN: http://ssrn.com/abstract=321520

Jensen, Michael C., "Agency Costs of Overvalued Equity" (March 2005). Harvard NOM Working Paper No. 04-26; ECGI - Finance Working Paper No. 39/2004, Financial Management, V. 34, No 1, Spring 2005. http://ssrn.com/abstract=480421

Jensen, Michael C., "The Agency Cost of Overvalued Equity and the Current State of Corporate Finance". Harvard NOM Working Paper No. 04-29, European Financial Management, Vol. 10, pp. 549-565, December 2004 http://ssrn.com/abstract=560961

Jensen, Michael C. and Erhard, Werner, A 'Value-Free' Approach to Values (PDF File of Powerpoint Slides) (April 11, 2011). Harvard Business School NOM Unit Working Paper No. 11-010; Barbados Group Working Paper No. 10-06; Simon School Working Paper No. FR10-26. Available at SSRN: http://ssrn.com/abstract=1640302

Jensen, Michael C., Murphy, Kevin J. and Wruck, Eric G., "Remuneration: Where We've Been, How We Got to Here, What are the Problems, and How to Fix Them" (July 12, 2004). HBS NOM Paper No 04-28; ECGI - Finance Working Paper No. 44/2004. http://ssrn.com/abstract=561305

J. R., "UBS and Libor: Horribly Rotten, Comically Stupid” Economist Column: Schumpeter: Business and Management, 12-19-2012 http://www.economist.com/blogs/schumpeter/2012/12/ubs-and-libor (Accessed Feb. 27, 2013.) 
Jewish Virtual Library: Bernard Madoff.

http://www.jewishvirtuallibrary.org/jsource/biography/Bernard_Madoff.html Jewish Virtual Library (Accessed Feb. 25, 2013)

Kahneman, Daniel. 2011. Thinking, Fast and Slow. London: Penguin.

Kahneman, Daniel. "Nobel Prize Autobiography”, accessed March 4, 2012 http://www.nobelprize.org/nobel_prizes/economics/laureates/2002/kahneman-autobio.html

Kahneman, Daniel and Amos Tversky. "Prospect Theory: An Analysis of Decision under Risk". Econometrica, 47(2), pp. 263-291, March 1979

Kothari, S. P, Elena Loutskina, and Valeri Nikolaev. 2005. "Agency Theory of Overvalued Equity as an Explanation for the Accrual Anomaly", (December 22, 2005). http://ssrn.com/abstract=871750

Kuhn, Thomas S. 1996. The Structure of Scientific Revolutions. Chicago: University of Chicago Press.

Lauricella, Tom, 2003, "Strong Steps Down From Board But Stays On as Head of Firm," Wall Street Journal (Nov. 3).

Lauricella, Tom, and Christopher Oster, 2003, "Second Strong Executive Snagged in Probe Anthony D'Amato of CEO's Office Was Involved in a Deal to Allow Canary to Rapidly Trade Shares," Wall Street Journal (Nov. 19).

Lauricella, Tom, and Christopher Oster, 2004, "Strong Funds And Regulators To Settle Case Agreement Would Clear the Way For Possible Sale to Wells Fargo; Considerable Challenges Ahead," Wall Street Journal (June 5, 2008).

"Libor (Barclays interest Rate Manipulation Case)" New York Times, March 3, 2013, http://topics.nytimes.com/top/reference/timestopics/subjects///london_interbank_offered_rate _libor/index.html (accessed March 3, 2013)

Lin, Hsiou-wei and Maureen F. McNichols. 1998. "Analyst Coverage of Initial Public Offerings": Stanford University. Unpublished manuscript.

Lin, Hsiou-wei and Maureen F. McNichols. 1998. "Underwriting Relationships, Analysts' Earnings Forecasts and Investment Recommendations." Journal of Accounting and Economics, V. 25, No. 1: pp 101-127.

Lin, Hsiou-wei, Maureen F. McNichols, and Patricia C. O'Brien. 2003. "Analyst Impartiality and Investment Banking Relationships": National Taiwan University, Stanford University, and University of Waterloo. Unpublished Manuscript. 
Ljungqvist, Alexander, Malloy, Christopher J. and Marston, Felicia C., "Rewriting History" (February 20, 2007). AFA 2007 Chicago Meetings Paper Available at SSRN: http://ssrn.com/abstract $=889322$

Marquardt, Carol and Wiedman, Christine I., "How are Earnings Managed? An Examination of Specific Accruals" (December 2002). http://ssrn.com/abstract=375660

Matsumoto, Dawn A. 2002. "Management's Incentives to Avoid Negative Earnings Surprises." Accounting Review, V. 77, No. 3: pp. 483-514.

McLaughlin, David, "BofA Probed by New York Over Mortgage Securities", Bloomberg (March 1, 2013), http://www.bloomberg.com/news/2013-03-01/bofa-probed-by-new-yorkover-mortgage-securities.html (Accessed March 3, 2013)

McNichols, M., and P. O’Brien, 1997, Self-selection and analyst coverage, Journal of Accounting Research 35 (Supplement), 167-199.

Michaely, R., and K. L. Womack, 1999, "Conflicts of Interest and the Credibility of Underwriter Analyst Recommendations," Review of Accounting Studies, V. 12: pp. 653-686.

Murphy, Kevin J. "Executive Compensation: Where We Are, and How We Got There," Chapter 4 in George Constantinides, Milton Harris, and René Stulz (eds.), "Handbook of the Economics of Finance". Elsevier Science North Holland (forthcoming 2013)

Murphy, Kevin J. and Jensen, Michael C., "CEO Bonus Plans: And How to Fix Them" (November 19, 2011). Harvard Business School NOM Unit Working Paper 12-022; Marshall School of Business Working Paper No. FBE 02-11. Available at SSRN: http://ssrn.com/abstract=1935654

Myers, James N., Myers, Linda A. and Skinner, Douglas J., "Earnings Momentum and Earnings Management" (April 2005).http://ssrn.com/abstract=741244

New Oxford American Dictionary. Edited by Angus Stevenson and Christine A. Lindberg. Oxford University Press, 2010.

New York Times, March 3, 2013, "Libor (Barclays interest Rate Manipulation Case)", March 3, 2013 http://topics.nytimes.com/top/reference/timestopics/subjects///london_interbank_offered_rate _libor/index.html (accessed March 3, 2013)

O'Brien, Patricia C. 1990. "Forecast Accuracy of Individual Analysts in Nine Industries." Journal of Accounting Research, V. 28, No. 2 (Autumn 1990): pp 286-304.

O’Toole, James, and Charles Riley, "HSBC Pays \$1.9 Billion To Settle US Probe”, CNNMoney (December 11, 2012) http://money.cnn.com/2012/12/10/news/companies/hsbc-moneylaundering/index.html (accessed March 3, 2013) 
Phenomenology Online. http://www.phenomenologyonline.com/inquiry/11.html (accessed 21 December 2010).

Pool, Veronika Krepely and Bollen, Nicolas P.B., "Do Hedge Fund Managers Misreport Returns? Evidence from the Pooled Distribution" (November 19, 2007). Available at SSRN: http://ssrn.com/abstract=1018663

Protess, Ben, and Mark Scott, 2012. "Barclays Settles Regulators' Claims Over Manipulation of Key Rates", Dealbook, June 6, 2012, http://dealbook.nytimes.com/2012/06/27/barclays-saidto-settle-regulatory-claims-over-benchmarkmanipulation/?ref=londoninterbankofferedratelibor

Rajan, Raghuram and Henri Servaes. 1997. "Analyst Following of Initial Public Offerings." Journal of Finance, V. 52, No. 2: pp 507-529.

Rangan, S. 1998. Earnings management and the performance of seasoned equity offerings. Journal of Financial Economics 50: 101-22.

Rawls, John. 1971. A Theory of Justice. Cambridge, MA: Belknap Press.

Rawls, John. 2001. Justice as Fairness: A Restatement. Cambridge, MA: Belknap Press.

Richardson, Scott, Siew Hong Teoh and Peter Wysocki. 2004. "The Walk-down to Beatable Analyst Forecasts: The Role of Equity Issuance and Insider Trading Incentives." Contemporary Accounting Research, V. 21, No. 4: Winter, pp. 885-924.

Scott, Mark, and Ben Protess, “As Unit Pleads Guilty, UBS Pays \$1.5 Billion Over Rate Rigging”, Dealbook, Dec. 19, 2012, http://dealbook.nytimes.com/2012/12/19/as-unit-pleadsguilty-ubs-pays-1-5-billion-in-fines-over-rate-rigging/ (accessed March 3, 2013)

Searle, John. 1969, Speech Acts: An Essay in the Philosophy of Language, Cambridge, UK: Cambridge University Press.

SEC, Securities and Exchange Commission, "Goldman Sachs to Pay Record \$550 Million to Settle SEC Charges Related to Subprime Mortgage CDO”, July 15, 2010. http://www.sec.gov/news/press/2010/2010-123.htm

Skinner, Douglas J., and Richard G. Sloan, 2002, Earnings Surprises, Growth Expectations, and Stock Returns or Don't Let an Earnings Torpedo Sink Your Portfolio, Review of Accounting Studies 7, 289-312.

Smith, Randal, and Tom Lauricella, 2006, "Moving the Market: Bear Stearns to Pay \$250 Million Fine; Net Rises 36\%," Wall Street Journal (March 17). 
Stewart, Bennett. 2004. "Making Financial Goals and Reporting Policies Serve Corporate Strategy: The Case of Progressive Insurance. An Interview with Tom King, VP and Treasurer, Progressive Insurance." Journal of Applied Corporate Finance, V. 16, No. 1: pp. 8-19.

Teoh, S., I. Welch, and T. Wong. 1998. Earnings management and the underperformance of seasoned equity offerings. Journal of Financial Economics 50: 63-99.

Thaler, Richard H., and Cass R. Sunstein. Nudge: Improving Decisions About Health, Wealth, and Happiness, Yale University Press, New Haven \& London, 2008.

Webster's New World Dictionary \& Thesaurus, Accent Software International, Macmillan Publishers, Version 2.0 - 1998, Build \#25. 